This item was submitted to Loughborough's Research Repository by the author.

Items in Figshare are protected by copyright, with all rights reserved, unless otherwise indicated.

\title{
Enterprise competence organization schema: publishing the published competences
}

PLEASE CITE THE PUBLISHED VERSION

http://dx.doi.org/10.1177/09544054JEM2097

PUBLISHER

Sage ( IMechE

VERSION

AM (Accepted Manuscript)

LICENCE

CC BY-NC-ND 4.0

REPOSITORY RECORD

Khilwani, Nitesh, Jennifer A. Harding, and Manoj K. Tiwari. 2019. "Enterprise Competence Organization Schema: Publishing the Published Competences”. figshare. https://hdl.handle.net/2134/9521. 
This item was submitted to Loughborough's Institutional Repository (https://dspace.lboro.ac.uk/) by the author and is made available under the following Creative Commons Licence conditions.

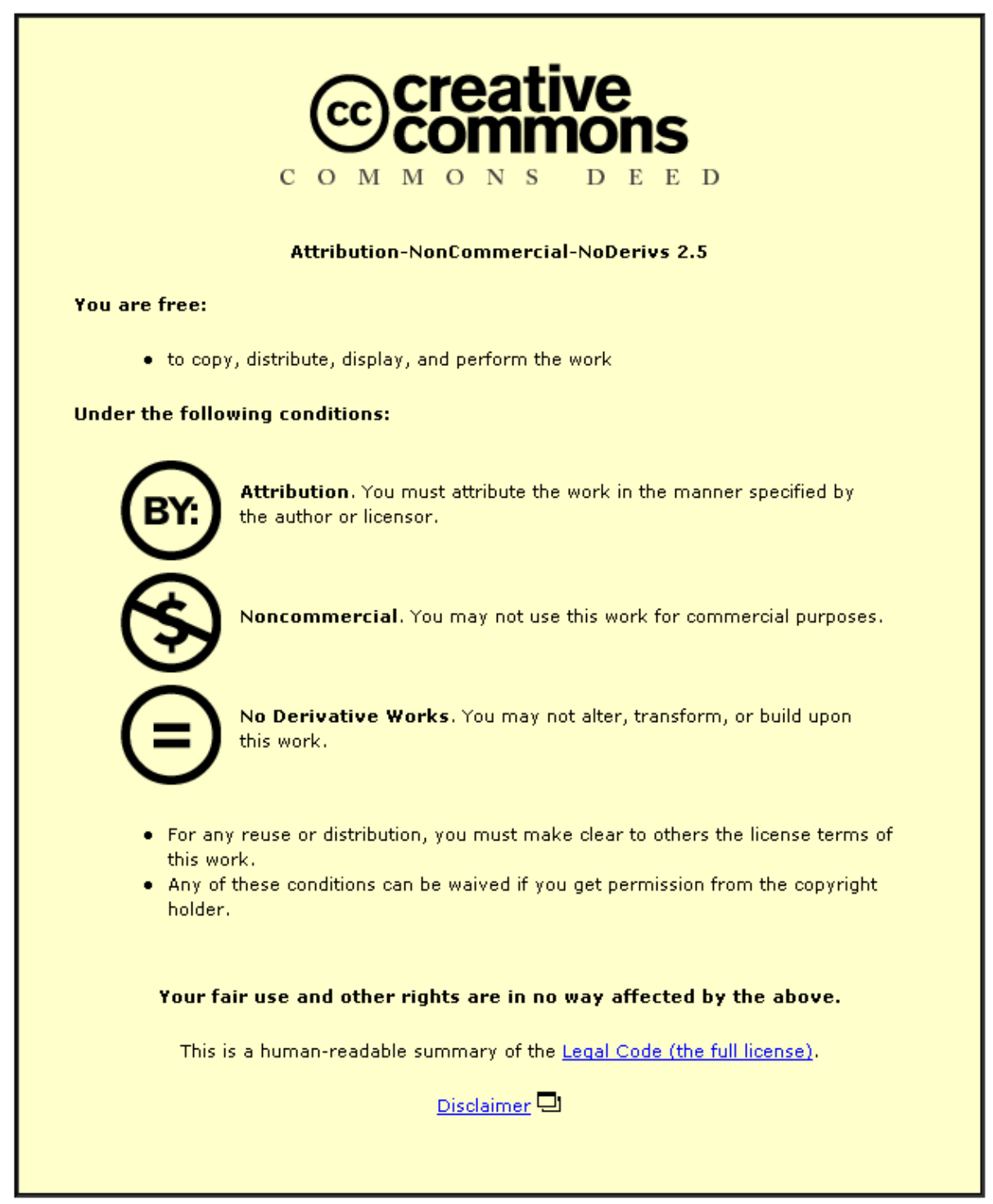

For the full text of this licence, please go to: http://creativecommons.org/licenses/by-nc-nd/2.5/ 


\title{
ECOS: Publishing the Published Competences
}

\author{
Nitesh Khilwani $^{1}$, J. A. Harding ${ }^{1 *}$, M. K. Tiwari $^{2}$
}

\begin{abstract}
Competence is a standardized way to define profile of an enterprise. Understanding and auditing competencies acquired, required and desired by a company and further representing them in a structured manner is a beneficial step for enhancing their performance. Ontology is emerging as an effective tool to structure competences for comprehensive and transportable machine understanding. In this paper, ECOS (Enterprise Competence Organization Schema) is presented as a mechanism to capture enterprise competence in a computer understandable manner. The objective behind this concept is to create a web of machine readable pages describing basic information and competences of enterprises with sets of interconnected data and semantic models. The ECOS ontology captures enterprise competences using a consistent and comprehensive list of concepts and vocabulary and converts them into a semantic web resource using the Web Ontology Language (OWL). The novel concept of an ECOS-card and ECOS-form is proposed and used for developing and publishing enterprise competences. Examples from real life enterprise applications of ECOS are also shown in this paper.
\end{abstract}

Keywords: Enterprise Competence, Competence Management, Ontology, Web Ontology Language (OWL), ECOS-card, ECOS-form

Ontologies: ECOS ontology, vCard ontology

Classifications: International Standard for Industrial Classifications (ISIC), Central Product Classification (CPC), Nomenclature of Territorial Units for Statistics (NUTS), International Standard Classification of Occupations (ISCO)

\footnotetext{
${ }^{1}$ Wolfson School of Mechanical and Manufacturing Engineering, Loughborough University, UK

${ }^{2}$ Department of Industrial Engineering and Management, Indian Institute of Technology, Kharagpur, INDIA

* Corresponding Author: J.A.Harding@lboro.ac.uk
} 


\section{Introduction}

With the advent of information and communication technologies, numerous formal and informal networks are emerging among organizations and individuals [1]. Traditional notions of enterprises with clear boundaries and limited relationships are no longer adequate. In order to compete with the global giants, enterprises are looking beyond self-centred passive environments and are trying to form inter-enterprise networks to succeed and achieve business goals [2]. However, creation of a collaborative alliance is a difficult process that requires strategic and management decision making processes about the selection of partners. To support these processes, the need is to store, update, share, promote and transfer each partner's skills and abilities efficiently [3, 4]. Apart from this, it is important to recognize and manage the knowledge and skills of their internal competence.

Considering the industrial requirements in mind, it is necessary to capture the skills and abilities of enterprises in a formalized manner (as profiles). Awareness of these profiles is a beneficial step to envisage and plan execution of new missions, to make a better appraisal of human capital, to initiate and mediate partnerships and to enhance organizational performance [5]. Enterprise competence profiles are usually captured and published as text documents, such as web homepages, industrial profiles, business cards etc. Such unstructured documents are selfcontained sets of ideas delineating certain information about the company [6]. It is necessary to develop a standard mechanism for modelling, management and exchange of competence information in more explicit and structured manner.

In literature, competence models have continuously been used to consolidate and contextualize enterprise competence in an explicit and structured manner [7, 8]. Competence is a crucial factor in business scenarios that give a deeper description about the profile of an enterprise and individual [9]. Such profile demonstrates the knowledge, skills, experience, and attributes necessary to carry out a defined function effectively. In the past, competency was handled by humans having good knowledge about acquirements and requirements of the firms [10]. In the current situation, where global markets and partnerships are increasing, it is really difficult to handle information about all the collaborative firms and hence it is necessary to model the knowledge in a form that is manageable and addressable [11].

In this paper, ECOS (Enterprise Competence Organization Schema) ontology is introduced to represent the published competences of enterprises. Ontology based knowledge representation is a powerful scheme to model 
concepts and relationships that allow knowledge to be designed, shared and reused in a disciplined way [12]. ECOS captures the domain knowledge and establishes common vocabularies which can be understood by systems as well as humans. It is used to capture, organize and publish enterprise competence under four fundamental domains i.e. general information, business details, specific information and business records and is further represented through an explicit ontology language (OWL) that can be interpreted by software as well as humans $[13,14]$. The novel concept of an ECOS-card is proposed in this paper to publish enterprise competence as a standard electronic business card. It is proposed to enhance the manageability of enterprise competence, generally available as unstructured text documents and enable software agents to carry out sophisticated task e.g. planning, evaluation, profile matching, need analysis, etc. A simple web application, named ECOS-form, has been developed to create ECOS-card and publish it on web.

The objective of ECOS is to create a web of machine readable pages and utilize it to support enterprises in constructing and maintaining their own competences, evaluating their competences, matching their own competences with others and finding others with desired competences in appropriate domains. It can be used in various enterprise applications such as selecting suitable partners, identifying appropriate tenders, finding certain competencies, etc. The novelty of our paper resides in providing an ontology modelling technique to represent the enterprise competence. ECOS is developed to represent the enterprise competence and is used, for the first time, to publish information in the form of ECOS-card, a machine readable page in RDF/XML format.

The organization of the paper is as follows: Section 2 provides brief detail about enterprise competence, related literature on enterprise ontologies and competence management. Section 3 is the discussion on motivation and objectives for the development of ECOS model. In section 4, definition and details about ECOS ontology model are provided. Section 5 provides a simple example explaining the implementation of ECOS. In section 6, real life application areas for ECOS model are provided. Finally, conclusions for this paper are given in Section 6.

\section{Enterprise Competence: Concept and Trend}

Any company willing to enter a global market must publish their competences e.g. skill, capability, expertise, etc that they are able to offer. When enterprises are considered, competences include business activities, products or services produced and their preferences. Enterprise competence defines the skills and abilities of an organization to 
carry out certain type of tasks based on knowledge and experience of its methods and resources, as shown in figure 1. This is the ability to coordinate the deployment of company's assets in ways that gives competitive advantage and produces success in the market place. Competence is a new way to consider relationships among individuals, groups and organizations, associated with a new vision of performance as well as new forms of management and decision making [5]. Understanding and sharing competences improves performance of the firms in the following aspects [19]:

- attract, retain and improve the best available resources for creating and realizing continuous value creation and distribution,

- publish the competence of one's own firm in the market and identify potential cooperation opportunities,

- increase awareness about one's own current capabilities as well as understand competences that other companies can offer, which can be used to identify areas for future development, and

- initiate or mediate new partnerships.

\subsection{Related Literature}

Modelling and management of enterprise competence refers to how information is managed with respect to organization, groups and individuals [16]. Specialized knowledge services are used to extract knowledge and represent them systematically in a formalized manner [7]. Ontology modelling is one of the tools that provide an explicit description of real world knowledge [12]. The term ontology has been coined from philosophy, as a branch of meta-physics concerned with the systematic explanation of existence. Due to its strong implications for conception of reality, it has gained much interest in artificial intelligence for defining the basic terms and relationships comprising the vocabulary of a topic area as well as the rules for combining terms and relations to define extensions to the vocabulary. It is utilized in knowledge representation, knowledge engineering, information modelling, data base development and integration, information retrieval and extraction, etc [3, 12, 21, 22]. It basically contains concepts, concept taxonomies and relationships to support information exchange and knowledge sharing.

There is a plethora of literature related to the development of ontology models [3, 23, 24]. But there are only a handful of efforts that have attempted to model enterprise competence related information in a formal ontology. However, other work has been done to make this modelling process easier or has modified it for a particular purpose. 
Without any pretention of providing an exhaustive review of the published literature, some of the most relevant contributions in the area of enterprise modelling and competence modelling are summarized in next two sections respectively.

\subsubsection{Enterprise Ontologies and Modelling Framework}

Enterprise ontology models are generally used for enterprise knowledge management with well defined terminology accepted by all participating firms. The goal of an enterprise ontology model is to define semantics for the domain terminology in an easy to understand way. Such an ontology model is similar to dictionary, taxonomy or glossary, but with structures and formalisms that enable computers to process its contents. The goal of an enterprise ontology model is to define $[25,26] .:$

- business entities and relationships of enterprise,

- $\quad$ processes and planning,

- $\quad$ structure of organization

- $\quad$ market details and products/services.

- $\quad$ high level planning and preferences of enterprise.

Some important enterprise ontologies developed by the artificial intelligence community and enterprise modelling community are [23]:

1. TOVE: TOVE (TOronto Virtual Enterprise) is developed to support enterprise integration with minimum ambiguity and maximum understanding and precision in communication [27]. TOVE provides a generic and reusable ontology for modelling enterprise. It is basically the group of ontologies comprising of three different categories of ontologies viz. core ontologies for products and services; derivative ontologies for transportation and inventory; and enterprise ontology for enterprise design and business processes.

2. Enterprise Ontology: Enterprise Ontology is developed under the Enterprise project to provide collection of terms and definitions relevant to business enterprise [28]. Enterprise Ontology was not developed for a specific type of enterprise, but as a generic model oriented toward business and organization than towards specific domain.

3. Open Information Model (OIM): The goal of OIM project, sponsored by Meta Data Coalition (MDC), is to provide a vendor-neutral and technology-independent specification of enterprise meta-data [29]. The major 
components of OIM are: Analysis and Design Models, Objects and Components Model, Database and Data Warehousing Models, Knowledge Management Models, and Business Engineering Models. The major concepts defined in Business Engineering component deals with the organizational aspect of enterprise models.

4. CIMOSA: CIM-OSA (Computer integrated manufacturing open system architecture) is a methodology developed at Purdue laboratory for appropriate integration of operations by means of efficient information exchange within the enterprise [30, 31].

5. IDEON: A unified enterprise ontology that provide a common foundation for designing, reinventing, managing and controlling collaborative, distributed enterprises [23]. It consists of a set of business entities and relations that represent common entities with an enterprise context.

6. BPML (Business Process Modelling language) represents a new family of process definition languages intended for expressing abstract and executable processes that address all aspects of enterprise business processes [32]. It provides an abstract execution model for collaborative and transactional business processes based on the concept of a transactional finite state machine.

7. CNO (Collaborative Network Organization): In order to share same terminology, the Virtual Enterprise Partners need to agree on the terms that they intent to use in collaboration. CNO is introduced to structure concepts and terms used in the field of collaborative networks [65].

A detail survey on each of these ontologies and other relevant enterprise ontologies and modelling frameworks is reviewed in [64].

\subsubsection{Competence Modelling}

Competence modelling and management presents specific requirements in enterprise modelling. Enterprise competence models are generally used for representing relevant business activities and products or services offered/searched by the company. The HR-XML Consortium has defined competence as [33]:

"A specific, identifiable, definable, and measurable knowledge, skill, ability and/or other deployment-related characteristic (e.g. attitude, behaviour, physical ability) which a resource may possess and which is necessary for performing an activity within a specific business context."

Several competence analysis and management tools have been explored during the last few years. The Resourcebased view (RBV) is one of the initial approaches, used for identifying the internal capabilities and competences of 
an organization. Resource based theory sees enterprises as potential creators of value added capabilities and develops a rigorous model for analysing firm's strengths and weaknesses. The concept of RBV was coined by Edith Penrose in her book "The Theory of the Growth of the Firm" [67], where she argued that a firm is not the same thing as 'flesh and blood' organizations, it is collection of productive resources the disposal of which between different users and over time is determined by administrative decisions. However, the theory was popularized by Prahalad and Hamel [70], Rumelt [71], and Barney [68].

Within the resource based view, a company is considered as a pool of hard-to-copy resources and capabilities that reside within an organization and that the organization might want to develop, in order to achieve a sustainable competitive advantage. Resources and capabilities that are valuable, uncommon, poorly imitable and nonsubstitutable comprise the company's core competencies and therefore present a lasting competitive advantage [69]. In order to analysis the competitive potentials of core competences, Barney proposed a framework, VRIO, as an internal tool of analysis. VRIO analysis (Valuable, Rare, Inimitable, Organized) provides a checklist with the question of Value, the question of Rarity, the question of Imitability (Ease/Difficulty to Imitate), and the question of Organization and determines the strategic importance of resources and capabilities.

Pareto and Snis proposed a flexible interactive visualization model to support competence management from the perspectives of organizations, groups as well as individuals [35]. Harzallah et al. built a CRAI (CompetenceResource-Aspect-Individual) competence model which is useful for different competence management processes, e.g. enterprise competence identification, personnel recruitment, etc [36]. According to Schmidt and Kunzmann, an enterprise uses competence in two different perspectives, i.e. at the organizational level for integrating human assets into management practice and at the operational level for fostering learning activities of individual employees [37]. They developed a reference ontology to bring the above two perspectives together. Draganidis et al. developed an ontology based tool for competence management [38]. Yu et al. developed an Enterprise Competence Model (ECM) for structural representation and exchange of competence within and outside the enterprise [9].

Tarassov et al. modelled an individual and industrial competence model using ontology as a meta-model [39]. They utilized ontology as a way to formalize individual and industrial competence. Boucher et al. has done a general survey on the formalisation and integration of competence oriented concepts within enterprise information system and decision systems [10]. Pepiot et al. proposed UECML (Unified Enterprise Competence Modelling Language) with the intension of providing a neutral interface for enterprise competence modelling [40]. This 
language is developed to alleviate the deficiencies of UEML (Unified Enterprise Modelling Language) and making a simple and single model for competence modelling. Mariethoz and Probst came with Business Concept Ontology (BusCO) modelling concepts related to the enterprise performance and competence monitoring processes [19]. BusCO gives a common understanding of the data and information which facilitate the analysis of the general and enterprise specific concepts related to competences and experience monitoring.

\subsection{Need for Published Competence Model}

To fully exploit enterprise skills and capabilities in a global market, it is necessary to consolidate and contextualize published competences in an explicit and structured manner. Published competence is a very crucial element for a company wishing to participate in collaboration [41]. A published competence consists of knowledge that the enterprise is willing to make public (or publish). It includes details that the company wants to tell others about who it is / what it can do / what it is interested in / what it wants to achieve etc. It emphasizes information that may affect relationships with individuals, groups and organizations, associated with a new vision of performance as well as new forms of management and decision making. Unfortunately, most of the models discussed above do not cover this requirement and are unable to represent entire competences with the same, single formalism $[19,38,40]$. In the context of this paper, the main deficiencies identified in existing literature and addressed in this research are:

- Enterprise ontologies are too general and mainly focus on single enterprise modelling.

- Competence models lack consistent set of concepts and vocabulary for describing competences.

The ECOS (Enterprise Competence Organization Schema) is therefore proposed in this paper in response to the incompleteness of existing work. The proposed ontology is based on the representation of published competences of enterprises in a formalized notion.

\section{ECOS: Motivation and Objectives}

The Web is a basic entity for interconnecting man and machine and almost all parts of the enterprise community have reshaped to exploit the opportunities offered by the Web [44]. Web technology is used to handle the information systems concerned with syntactic and structural heterogeneity [44, 45]. However knowledge sharing and communication among multidisciplinary enterprises require the treatment of structure as well as semantics of the data stored in those repositories [44, 46, 47]. Collaborating partners often use different terminologies to describe 
the same meaning or alternatively the same terminology may be associated with different meanings. Such lack of clear semantic description of the meaning of contents in a particular domain has hampered the interoperability and sharability of knowledge between collaborative firms. In order to handle this interoperability challenge of future organizations, it is necessary to make knowledge explicit and machine interpretable [20, 40].

The next generation enterprise community needs sets of interconnected data and semantic models to communicate and exchange their knowledge, without the current risk of misinterpretation. The Semantic Web is a vision for extending current web technology in which information is annexed with a well defined meaning that enhances the interoperability of computers and people [44]. This extension of the web employs ontologies for defining semantics and thus giving meaning to the data and applications for automatic processing. Ontologies are considered as one of the pillars of the Semantic Web having a collection of concepts and relations for a domain. The ECOS ontology is defined for expressing and sharing enterprise competence, defining common vocabularies for similar concepts and supporting intelligent queries over heterogeneous databases.

Such concept of proposing metadata (ontology for semantic web) was previously introduced in the form of the Friend-of-a-Friend (FOAF) vocabulary [48]. The FOAF project explored the application of semantic web technologies for describing a person's social sphere e.g. professional and personal lives, their friends and interests etc. Similarly, the vCard ontology was proposed as a metadata for an electronic business card [49]. ECOS, which is proposed in this paper, addresses the challenges of sharing enterprise competency knowledge in a similar manner, through a metadata for modelling and managing enterprise competence, publishing it on web and sharing and exchanging it with enterprises. ECOS does not aim to propose a definitive enterprise modelling language acting as a substitute for all previous proposed ontologies, rather it provides a standard meta-model for published competences of enterprises. ECOS and its developments contribute towards:

- Metadata for electronic business cards: Metadata is a machine processable information for the web; when structured into a hierarchical arrangement is known as ontology. Both terms describe "what exists" for some purpose and are used as a shared means of communication between computers and between humans and computers [12]. To reach this goal, information is attached with a semantic annotations so that it can be processed and used by computers. ECOS ontology provides a metadata for annotating information in a electronic business card and express it as a semantic resource. 
- Consistent set of concepts and vocabulary: Standards are used to represent competences with a consistent set of vocabulary, which is widely accepted and shared among enterprises. In an attempt to articulate a comprehensive vocabulary, classifications defined by United Nations Statistics Division and European Union are considered in this paper, see Appendix B. These international classifications, including CPC (Central Product Classification), ISIC (International Standard for Industrial Classification), NUTS (Nomenclature of Territorial Units for Statistics) and ISCO (International Standard Classification of Occupations), are converted into semantic web resources using SKOS (Simple Knowledge Organization Scheme [54].

- Interoperability with existing ontologies: In order to avoid reinvention of the wheel, existing ontologies are used for explaining certain ecos concepts. vCard ontology is used for capturing information about person and address in ecos ontology, see Appendix A [63]. Similarly, iCalendar ontology is used for capturing time in ecos [66].

\section{ECOS: Definition and Details}

Apriori, to understand the implementation of ontologies in competence management, it is necessary to understand what they are. In recent times, ontologies have gained increasing interest from AI communities due to their capability to capture knowledge for representation, processing and management $[6,25,26]$. In situ, ontologies have been defined by several researchers in different ways but a definition that is most general and widely quoted is "an explicit and formal specification of a shared conceptualization", where explicit means it comprises concepts, properties, relationships, functions, axioms and constraints [50, 51,12]. Similarly, formal means it is machine readable and interpretable. Conceptualization is used as an ontology provides an abstract model which gives a simplified view of the things it represents and shared means there is consensus about the information which is acknowledged by a group of experts. In short, it is a set of concepts, its taxonomy, interrelations and the rules that govern such concepts.

The ECOS ontology proposed in the paper for modelling enterprise competence is shown in figure 2 . It is mapped as a generic tree structure to model the published competences of enterprises. The structure has been divided into 4 key classes, namely - General Information, Business Details, Specific Information and Records. The 7 stage ontology design process proposed by Noy and McGuinness [52] has been followed for developing the ECOS ontology. The knowledge engineering approach includes the following steps: 
1. Determine domain and scope of ontology: The domain and scope of ECOS is clear from the beginning. It is used to model published competence of enterprise.

2. Consider reusing existing ontology: In order to ensure interoperability of the ECOS ontology with other ontologies and to avoid reinvention of the wheel, existing ontologies (vCard ontology) and standards are included in proposed ontology.

- vCard ontology is used for expressing name, address information, phone etc of companies and individuals. The concepts and properties of vCard utilized in the ECOS ontology are given in Appendix A.

- Standard Classifications (given by Statistical division of UN) are used for developing a consistent set of vocabularies for enterprise competences (details in Appendix B). CPC codes (Central Product Classification) are used for products, tangible resources, etc; ISIC (International standard for industrial classification) for defining sector, skills, etc; ISCO (International Standard Classification of Occupations) for defining job roles.

3. Enumerate terms: The key concepts and relationships existing in the competence description have been identified and used for developing this structure. The model is developed with a consistent set of vocabulary and semantic definitions for concepts and relations. The terminologies used in this vocabulary set are defined using knowledge and experience of published information models on enterprise ontologies and competence models.

4. Define class and class hierarchy: The structure has been divided into 4 key classes, namely- General Information, Business Details, Specific Information and Records. These key classes are further divided into 16 classes in total.

5. Define properties of classes: The classes defined in the ECOS ontology are linked with a list of properties, 32 in total.

6. Define facets of slots: This step is covered in greater detail in the next sections.

7. Create instances: Instances of the ECOS ontology are shown in Section 6.

The detailed description of ECOS concepts are discussed in the following sub-sections. 


\subsection{ECOS Concepts}

ECOS is used to capture and publish enterprise competence in a machine as well as human understandable manner. It is based on a set of core concepts and sub-concepts required to describe enterprise competence. ECOS is based on four high level concepts that collectively represent the published competence of an enterprise:

\subsubsection{General Information}

An ECOS representation starts with General Information, capturing basic information about the company such as name, address, contact person etc. General Information consists of 5 concepts:

- Company Name $(G C N)$ : Includes the name of the enterprise added with a URI (Unique Resource Identifier), such that:

$$
G C N=\langle\text { name }, U R L\rangle
$$

name is the name of company. $U R L$ is a basically a web link that leads to a web page (e.g. homepage) on World Wide Web (WWW). It is used to give a unique name to each enterprise in our database.

- Summary $(G S)$ : Stores a brief description about the enterprise. This concept is used to capture a concise opening paragraph about the company.

$$
G S=\langle\text { summary }\rangle
$$

- Address (GA): This concept expresses the contact address of the enterprise, including address, phone numbers, etc. vCard ontology is used to express an enterprise address's in the ECOS model, such that:

$$
G A=\left\langle\{v \operatorname{card}\}, G A_{\text {code }}\right\rangle
$$

where, $G A_{\text {code }}$ is the NUTS code referring to the region of the enterprise.

Contact Person (GCP): Terms defined in the vCard ontology are used to describe information about the contact person of the company.

$$
G C P=\left\langle\{v C a r d\}, G C P_{\text {code }}\right\rangle
$$

where, $G C P_{\text {code }}$ is the ISCO (International Standard of Occupation) code selected for the contact person.

- Key Person (GKP): This concept is used to give information about key people responsible for managing the business and affairs of the company and ensuring its success. It is also expressed using the vCard ontology and ISCO codes. 


$$
G K P=\left\langle\{v \operatorname{Card}\}, G K P_{\text {code }}\right\rangle
$$

This concept may include information about lead persons in the company such as shareholder, owner, director, etc. $G K P_{\text {code }}$ is ISCO code representing role of person.

\subsubsection{Business Details}

This key class is intended to capture the market details of a company. It includes information about sector, product/services, customers, preferences and financial details of the company.

- Sector $(B S)$ : This concept refers to a broad way of grouping similar industries. Generally, enterprises are classified in four key sectors: the primary sector, largely raw material extraction industries such as mining and farming; the secondary sector, involving refining, construction, and manufacturing; the tertiary sector, which deals with services (such as law and medicine) and distribution of manufactured goods; and the quaternary sector, a relatively new type of knowledge industry focusing on technological research, design and development such as computer programming, and biochemistry. A fifth quinary sector has been proposed encompassing non-profit activities. In this paper, Sector codes are used to classify companies into different sectors. Formally, the sector concept is defined as:

$$
B S=\left\langle B S_{\text {code }}\right\rangle
$$

where, $B S_{\text {code }}$ is the first level of ISIC code used for defining enterprise sector (Appendix B).

- Products/Services (BPS): Generally, the description of product/service includes information about, what it is, what is does and its features and benefits. Keeping the above requirements in mind, this concept captures the description as:

$$
B P S=\left\langle\text { name, } B P S_{\text {code }}, \text { detail }\right\rangle
$$

where, name refers to the formal name of the product, $B P S_{\text {code }}$ is the list of CPC code (Central Product Classification) used for classifying product, detial includes further information about the product defined under data type properties: price, description, specification, purpose, etc.

- $\quad$ Customers $(B C)$ : This concept lists the potential buyer or user of products/services of the company. This is typically through purchasing or renting of goods or services. Formally, it is defined as:

$$
B C=\langle\{G I\},\{B S\}\rangle
$$


where, $G I$ is the general information about the customers, $B S$ is used to define the sector code of the customers.

- Financial Highlights (BFH): The financial details of the company include information about their revenue, profit, income, employee etc. This information is captured under this concept, formally defined as:

$$
B F H=\langle\text { name }, \text { value }, \text { time }\rangle
$$

where, name is the type of information, value is the value of name and time is the time when this information is captured.

- Preferences $(B P)$ : Enterprises always look for new business opportunities in the market, but with a focus on certain objects of interest. This concept in included to capture those business interests of the company. It is formally defined as:

$$
B P=\langle\text { type }, \text { value }, \text { weight }\rangle
$$

where, type is a the type of preference such that type $=\{$ sector, region, process, product $\} ;$ value is the value of the preference selected from standard classifications, where sector $\in$ SectorCode, region $\in$ NUTS, process $\in I S I C$ and product $\in C P C$; weight represents the numerical weight of the enterprise preference.

\subsubsection{Specific Information}

The central idea for this key class is to capture core competences of an enterprise. Core competences consist of all assets, both tangible and intangible, human and non-human that are possessed and controlled by the company and that permit it to devise and apply value enhancing strategies [69]. The Specific Information class captures these competences under five sub-classes that are:

- Process (SP): This concept defines the activities and programs that a company employs to meet its mission, objectives and interests. A process is basically a sequence of actions resulting in a product or service. In general, the description of process includes, process name, description, actors involved in the process, its start and finish time, sequence of activity, etc. However, in ECOS model only description the information about published competence is included. Therefore, the formal description of $S P$ includes: 


$$
S P=\left\langle\text { name }, S P_{\text {code }}, \text { detail }\right\rangle
$$

where, name is the name of the process, $S P_{\text {code }}$ is one or more ISIC codes defined for the process, and detail is the description of the process.

- $\quad$ Resource (SR): Resources are entities used by processes in the day to day operation of the organization. This concept captures information of such entities that support the execution of processes. Resources can be classified in two categories, material and non-material resources [40]. A resource (SR) can be formally defined as:

$$
S R=\left\langle\text { name }, \text { type }, S R_{\text {code }}, \text { detail }\right\rangle
$$

where, name is the name of the resource, type is the type of resource such that type $=\{$ Material, Non-material $\}, S R_{\text {code }}$ is the CPC/ISIC code selected for the resource and detail is the description of the resource

- Unit (SU): This concept captures information about an organizational unit holding responsibility for identified processes and resources. A Unit is formally defined as :

$$
S U=\left\langle\text { name }, S U_{\text {code }}, \text { detail, actor }, \text { responsibility }\right\rangle
$$

where, name is the name of the organizational unit, $S U_{c o d e}$ is the ISIC code identified for the $S U$, detail is the details about the organizational unit, responsibility is a set of processes and resources such that responsibility $=[\{S P\},\{S R\}]$ and actor is the set of human resources used to support the handling responsibilities.

- Skill (SS): It is the ability to handle responsibilities and perform actions as per the requirements. It is repeatable pattern of action executed to create, produce and/or offer product/services to the market. Skills arise from the coordinated activities of resources, processes in an organization unit. A skill is formally defined as:

$$
S S=\left\langle\text { name }, S S_{\text {code }}, \text { detail }\right\rangle
$$

where, name is the name of the skill, $S S_{\text {code }}$ is the ISIC code identified for skill and detail is the description of skill

- $\quad$ Plan (SPP): Enterprises are always in search of new business opportunities and must be prepared to take on new challenge based on their capabilities that they are able to perform, but which they may not carry out at 
present. This concept is used to captures such information that enterprise believes they can perform in future. Formally, plan in defined as:

$$
S P P=\left\langle\text { name }, S P P_{\text {code }}, \text { detail }\right\rangle
$$

where, name is the name of the plan, $S S P_{\text {code }}$ is the selected ISIC code and detail is the description of the $S S P$.

\subsubsection{Business Records}

Central to the Record Category is information that an enterprise publishes to draw the attention of customers and vendors for new business opportunities. This key class lists information about past activities, relations and achievements of the company, etc. The concepts included in this class are:

- $\quad$ Past Project (RPP): This concept lists past projects of the company handled independently or in collaboration with other company. Formally, it is defined as:

$$
R P P=\left\langle\text { name }, R P P_{\text {code }}, \text { detail,time, partner }\right\rangle
$$

where, name is the name of the project, $R P P_{\text {code }}$ is the list of selected ISIC/CPC codes for describing project, detail is the description of the project, time is for start and end time or period of the project, partner is the list of partners involved in the project.

- Relation (RR): An enterprise always maintains and publishes relations with customers, investors and other companies (competitors or collaborators) to develop new connections in global market. This concept capture that information, formally defined as:

$$
R R=\left\langle\text { name }, R R_{\text {code }}, \text { type }, \text { detail }\right\rangle
$$

where, name is the name of the company, $R R_{\text {code }}$ is the selected sector code, type is the type of relations, i.e. type $=\{$ Investor, Customer, Supplier, Collaborator, Competitor $\}$ and detail is the description about the relation.

- Achievements (RA): Companies often publish information about their achievements, including patents, standards, publication, etc. In ECOS, this information is captured as:

$$
R A=\left\langle\text { name }, R A_{\text {code }}, \text { type }, \text { detail }\right\rangle
$$


where, name is the name of the achievement, type is the type of achievements such that type $=\{$ Patent, Standard,Publication $\}, R A_{\text {code }}$ is the ISIC/CPC code selected for achievement and detail is the details of the $R A$.

\subsection{ECOS-card}

The standard Web Ontology Language, OWL, is used for publishing the schema and vocabulary of ECOS ontology on the semantic web [13]. The detailed description of the OWL schema is provided in Appendix C. The OWL schema provides a standard vocabulary for representing enterprise information in ECOS-format and publishing it on the web. The OWL schema developed for the ECOS ontology consists of 25 classes, 15 properties and 6 existing ontologies. Out of 25 classes in total, 5 are main classes used to describe general information, business details, specific information and business records of the enterprise class. The other 20 classes are auxiliary classes used for describing the main ones and their relationships. Table 1 explains classes, subclasses, properties and external ontologies utilized in ECOS ontology. The schema for EOCS ontology can be obtained on the web at: http://kmm.lboro.ac.uk/ontology/ecos.

The OWL schema for the ECOS ontology is used for generating an ECOS-card, figure 3, a concept proposed in this paper to create a semantic profile of an enterprise using the ECOS vocabulary. It is a novel concept of publishing information in a machine as well as human readable manner. As shown in figure 3 , an enterprise profile is represented in two formats i.e. human readable (front) and machine readable (back). The human interpretable page is written in plain HTML/XML format to view it in web browsers; whereas, RDF/XML format is used for representing machine readable information. Computers can use this card for finding information about a company or searching for companies whish have certain competences. This can also be used to facilitate the process of search engines and other search applications (e.g. tender selection, partner search) to work semantically.

\subsection{ECOS-form}

The ECOS-form is a simple web application developed to create an ECOS-card. It provides a platform for developing an ECOS-card in RDF/XML format. The ECOS-form is available on the web, http://kmm.lboro.ac.uk/ecos.html. It is an application form with fields for all sort of information required for 
creating an ECOS-card. A classification list for standard classifications is also provided with this form to define and add codes with enterprise information.

\subsection{ECOS Query}

$\mathrm{RDF} / \mathrm{XML}$ format, used for representing ECOS profiles, is the most common approach for linking data with ontologies. It is a W3C standard format for storing arbitrary data on the semantic web. The data in RDF/XML format is described as instances of the corresponding ontology represented as anRDF schema or OWL ontology. The advantage of statement-centric RDF data format is that it can be stored in various formats. For example, graph based representation, which is especially suitable for humans because it is easily readable. Other forms of representations include XML syntax which is more verbose but more popular on the web; and N-3 or N-triple, less verbose and better readable, but rarely used and known. However, in this paper RDF/XML syntax is used for storing ECOS profiles. An advantage of using an established syntax for ECOS is to gain existing advantages of XML and have a variety of applications e.g. web publishing, web searching and automating web tasks, e-business applications, pervasive computing, etc.

For RDF/XML based syntax, the next requisite is a query language which can access the information stored in ECOS profiles. SPARQL is the query language proposed for the semantic web and is currently a W3C recommendation. More precisely, SPARQL is a query language for RDF. In syntax, SPARQL resembles SQL (Sequential Query Language) up to a great extent (like SELECT, WHERE, ORDERBY) but the difference is SQL works on relational database while SPARQL works on the RDF graphs.

\section{ECOS: A Simple Example}

One of the core goals of the semantic web is to attach metadata with information resources stored in distributed locations and use ontologies and reasoning to aggregate it. ECOS is proposed in this paper as a standard ontology for attaching metadata with enterprise competences and publishing it as a semantic profile on web. The ECOS ontology provides a metadata for annotating information in an electronic profile of a company and expresses it as a semantic resource which can be understood by systems as well as humans. The proposed ontology model utilizes standard classifications (i.e. UN Classifications e.g. NUTS, CPC, ISIC etc) and existing ontologies (e.g. vCard) to develop a consistent set of concepts and vocabulary for capturing enterprise competences. The structured and 
explicit enterprise profile is generated to enhance the manageability of enterprise competence, information which is generally only available as unstructured text documents and thereby enable software agents to carry out sophisticated tasks e.g. planning, evaluation, profile matching, need analysis, etc.

This section presents how the ECOS ontology captures, presents and publishes competence in a formalized structure. In this paper, the enterprise information is captured using the ECOS-form, a web application developed for generating semantic profiles of the companies. This semantic profile is called an ECOS-card and is published in $\mathrm{RDF} / \mathrm{XML}$ format and HTML/XML format for human and machine processing respectively.

In order to better understand this process, an example is provided, i.e.:

Consider an enterprise, ABCJ Limited, with varied competences skills and processes, looking for new business opportunities in the market. The enterprise is willing to publish its information on the web and enter the global market. At first, the enterprise publishes information about their competences. The enterprise uses the ECOS-form for creating a semantic web profile and publishing it as their ECOS-card. The ECOS-card can be utilized to envisage and plan the execution of new plans, initiate new business opportunities, and extend their business potential. This semantic profile is analyzed and compared with other ECOS-cards from other enterprises for the selection of suitable business opportunities and appropriate business partners and developing enterprise collaboration.

The web profile of the enterprise ABCJ Limited is as follows:

"ABCJ Limited is a SME located in Leicester, UK. The company provides network consultancy and support to the academic and health sector. They offer a total IT support from managing your computers and networks and for writing software for them. ABCJ serves charity, education/Training, health/medical, ICT and Public Sectors. The key processes of the company are: IT networks, wireless networking, data applications etc. The company has skills in software development, IT networks and IT consultancy. ABCJ has close relationships and certifications from Microsoft, Novell, Cisco and many other industry standard technology companies. ABCJ always looks for project in the field of support and maintenance in IT networks."

The approach followed for converting the above text profile into a semantic web resource is as follows:

1. Form fill up: The ECOS ontology has four complementary concepts for capturing the key competences of an enterprise. An ECOS-form provides different fields, per se ECOS concepts, that need information from the user. The information required from users falls under the following categories: 
- General Information: captures basic information about the company i.e. name, short summary, address, contact person and key person.

- Business Detail: includes information about sector, product/services, customers, preferences and financial details of the company.

- Specific Information: captures tangible and intangible assets of the company, i.e. resources, skills, processes, organizational units and plans.

- Business Records: list information about past activities, relations and achievements of the company.

A screen shot of the ECOS-form filled with the information of ABCJ limited in shown in figure 4. Once this basic information is filled, the next step is to fill appropriate codes for the required field.

2. Codes Identification: One of the objectives of the proposing ECOS was to represent competences with a consistent set of vocabulary, widely accepted and shared among enterprises. In an attempt to articulate a comprehensive vocabulary, classifications defined by United Nations Statistics Division and European Union are considered in this paper (Appendix B). These international classifications, including CPC, ISIC, NUTS and ISCO, are converted into semantic web resources using SKOS (Simple Knowledge Organization Scheme [54]) and appended with the ECOS-form. Simple Knowledge Organisation Systems (SKOS) is a family of formal languages designed for representation of thesauri, classification schemes, taxonomies or any other type of structured controlled vocabulary. SKOS is built upon RDF and RDFS, and its main objective is to enable easy publication of controlled structured vocabularies for the Semantic Web. These SKOS model for standard classification can be obtained on the web at:

- ISIC code: $\underline{\text { http://kmm.lboro.ac.uk/classification/isco }}$

- CPC code: http://kmm.lboro.ac.uk/classification/cpc

- NUTS code: http://kmm.lboro.ac.uk/classification/nuts

- ISCO code: http://kmm.lboro.ac.uk/classification/isco

- Sector code: $\underline{\text { http://kmm.lboro.ac.uk/classification/sec }}$

A simple example explaining how a CPC code available as web resource is represented as a semantic web resource is shown in figure 5. These classifications are used in ECOS model for providing a standard vocabulary for competence representation. A screen shot of ECOS-form with blanks for classification codes is shown in figure 6. From figure 6, it is clear that a user has to select an appropriate code from lists shown in figure 4 and 
fill the required blanks in the form. The concepts available in the ECOS-form that requires classification codes are as follows:

- Sector code: Sector, Customer, Preference and Relation

- NUTS code: Address

- ISIC code: Process, Resource, Unit, Plan, Past Project and Achievement

- $\quad$ PPC code: Products/Services, Resource, Past Project and Achievement

- ISCO Code: Contact Person, Key Person

3. ECOS-card Generation: Once the enterprise information and appropriate codes are filled in the required fields, an ECOS-card can be generated from the ECOS-form. The ECOS-card generated for above example is shown in

figure 7. A tree representation of the ECOS-card generated from the ECOS-form is shown in figure 8. For brevity, the tree structure of the ECOS-card is not shown completely. Only 3 concepts namely, ecos:companyName, ecos:Address, ecos:contactPerson, ecos:Skill and ecos:Preference are shown in the figure.

The remainder of the concepts are self explanatory.

As mentioned earlier, the ECOS-card for $\mathrm{ABCJ}$ limited is provided in two formats, i.e. HTML/XML (human readable) and RDF/XML (machine readable), describing the company's basic information and competences labelled with a predefined classification codes to it. Figure 9 shows how same information is represented in two different format. The main advantages of this card are: (1) a computer can view this information as an explicit tree structure (as shown in figure 8), (2) it can store information in any decentralized location, (3) it can find information and accomplish tasks without human direction (4) computer can extract information from this card using SPARQL query language, discussed in Section 4.5.

The semantic profile generated for publishing the enterprise competences can be used to identify direct and indirect relations with other enterprises profiles and business opportunities. These relations can be used as a basis for building social relationships and supporting various enterprise applications, network analysis, project selection, etc . Three such applications are discussed in the next section.

\section{ECOS Applications}

ECOS captures enterprise published competences (information willing to make public) with a consistent set of concepts and vocabulary and present/store it as a semantic web resource. These semantic profiles are directly linked 
with standard classifications and existing ontologies, as shown in Figure 10, thus indirectly linked with each others. These hidden relations can be used for match ECOS profiles and identify relations between them. It can be used to support various enterprise applications related to the competences of an enterprise. Three such successful applications are discussed in this section.

\subsection{Network analysis among enterprises}

An Enterprise in pursuit of emerging business opportunities publishes its competences in the market or on the web to extend their business processes and develop collaborations with similarly focused companies (with complementary competencies). ECOS can be used to create semantic profiles of companies and further utilize them for network analysis. Network analysis is the mapping and measuring of relationships between people, groups, organizations, or any information processing entities. The nodes in the network refer to the entities whilst the links show relationships between the entities. ECOS can be used to facilitate modelling and analysis of collaborative networks, for the following reasons:

- The purpose of network analysis and ECOS are similar: network analysis focuses on defining explicit relationships between entities; ECOS is deployed for defining and explicating concepts and relationships in a particular enterprise domain.

- ECOS uses a consistent set of concepts and vocabulary for describing competences. This consistent vocabulary set can facilitate the reasoning and inference mechanism of network analysis.

A simple example of network analysis among enterprise profiles is shown in figure 11. Figure 11 shows part of the NUTS ontology and part of an ECOS profile for two companies ABCJ Limited and Anchor Industries located in Leicester and Derby respectively. From the above ontologies it is easy to infer that both companies are located in East Midlands. Similarly, more complex relations can be defined using ECOS profiles.

\subsection{Tender Selection}

The introduction of the internet in the business environment has allowed companies to realize their selling and buying activities as well as their cross company communication through the World Wide Web. With the support of internet technology, different organizations e.g. companies, government agencies, academic institutes, service providers etc publish their tender needs electronically. Generally, companies are registered with some tender alert 
services or may use their built-in software for tender receiving and tender matching. These matching services list tenders based on resemblance to the company's profile with the tender requirements [55]. The ECOS profiles can facilitate this process by providing a computer understandable format with a consistent set of vocabulary for defining competences.

\subsection{Partner Selection}

Generally, companies get notices from tender alert service in which they could provide input in collaboration with other SMEs, but which they could not undertake individually. In such situations, an enterprise needs the support of other companies to fulfil the tender requirement. However, selection of appropriate business partners and sharing of resources with them is a difficult task and a prime challenge associated with enterprise collaboration [56]. In the past, a broker (i.e. usually a human) with good knowledge about companies was employed as a driving force for searching and recognizing market opportunities, planning and drafting collaboration, and estimating costs and revenues. In the current situation it is really difficult to handle the information about all the collaborative firms and thus, it becomes necessary to model the knowledge in a form that is manageable and addressable [57]. An ECOS model can be used here to capture domain knowledge and establish a consistent vocabulary which can be easily interpreted by the system as well as humans.

\section{ECOS Interoperability}

The ECOS Ontology is proposed for defining the semantics for enterprise information and giving meaning to the enterprise profiles for their automatic processing. The goal is to enable computers to process the interchanged information in a more intelligent way. The objective of ECOS is to create machine understandable pages with sets of interconnected data and semantic models that communicate and exchange knowledge and enhance the opportunities for enterprise collaboration. It can be seen as an enabling technology that allows the formalization of the semantics of enterprise information for its unambiguous interpretation. ECOS can contribute to solving the problem of interoperability between software applications across different organizations, providing a shared understanding for terminologies used in enterprise profiles. It can be used as a key element in various enterprise applications such as information search and retrieval, profile representation and management, etc. 
However, the standalone ECOS ontology is not adequate for all enterprise applications and domains as the enterprise community cannot agree upon using a single ontology to describe all its processes. The concern of this research is to manage the ontology in a manner that supports users to modify, integrate and reuse it with new and existing ontologies. Ontology integration and reuse is required to reduce the cost and effort spent in developing new ontologies. In the ECOS model, the vCard ontology is reused to capture information about enterprise individuals (e.g. name, address etc), instead of developing the model for person from scratch. Similarly, the proposed ECOS model can be reused in other ontologies from the enterprise and semantic web communities for managing enterprise competences profile information. The users can use the link, http://kmm.lboro.ac.uk/ecos/1.0\#, for integrating the ECOS ontology with existing and new ontologies.

Currently, the authors are planning to integrate the ECOS ontology with Linked Data, a sub-topic of the Semantic Web. Linked data is basically about exposing, sharing and connecting data via URI (Uniform Resource Identifiers) and HTTP (HyperText Transfer Protocol) on the web [73]. Underpinning the semantic web, it is the set of best practices for defining interconnected data, fixing standardized meanings and publishing semantic data on the web. It is used to link current web information at the data level and evolve the current web from a global information space of linked documents to one where both documents and data are linked. Tim Berners-Lee, inventor of the Web and proponent of the Semantic Web, outlined a set of rules for publishing linked data, paraphrased along the following lines:

1. Use URIs as names for things,

2. Use HTTP URIs so that people can look up those names,

3. When someone looks up a URI, provide useful information, using the standards (RDF, SPARQL),

4. Include links to other URIs, so that they can discover more things.

These 'Linked Data principles' provide the basis for publishing and connecting data using the infrastructure of the Web while adhering to its architecture and standards. The Linking Open Data (LOD) project, an open and collaborative effort by W3C SWEO Community, aimed to develop linked data by publishing open datasets as RDF and creating RDF links between data items from different data sources. The project started out in early 2007 with a relatively modest number of datasets and participants and has grown since both in terms of depth, impact and contributors. Currently LOD contains more than 40 datasets, with total volume above 4.7 billion statements, 
interlinked with 142 million statements as illustrated on Figure [73]. The idea is to link the ECOS ontology with this LOD dataset for publishing the enterprise profile information.

\section{Conclusion}

An enterprise regards the knowledge and skills of its internal competence as the primary wealth of the company and utilizes them to contribute to the distinctive features of the company. Competence plays a key role in enhancing organization performance. To enhance the organization's performance, it is essential to store, update, share, promote and transfer its skills and abilities efficiently. Ontology based knowledge representation is a powerful approach for modelling concepts and relationships that enable the management, sharing and reuse of knowledge in a disciplined way. An enterprise competence ontology model, named ECOS, is proposed here to capture the published competences and establish common vocabularies which can be easily interpreted by the system as well as human. ECOS is proposed with an idea of creating a web of machine readable pages describing companies, their basic information, skills, assets etc.

Acknowledgements: The authors thank the Innovative Manufacturing Construction Research Centre (IMCRC) at Loughborough University, and the SYNERGY - FP7-ICT-2007 (7th Framework Programme - ICT in support of the networked enterprise) EU Grant number 216089 project for support during this research.

\section{Appendix A}

\section{vCard Ontology}

vCard (aka. Versitcard) is a standard file format for electronic business cards. It was originally proposed in 1995 by the Versit consortium including Apple, AT\&T Technologies, IBM and Siemens. vCard is powerful means of Personal Data Interchange (PDI) used for exchanging information on emails, web etc. This is an electronic form of traditional business cards containing basic information such as name, address, phone numbers, URLs, logos, photographs, audio clips etc. In 2001, IPR Systems Pty Ltd specified a RDF (Resource Description Framework) framework for vCard profile. Resource Description Framework (RDF) is a W3C standard used for defining meta- 
data model. Iannella, R., used this language for developing a metadata model of vCard for semantic web [63]. In this paper, RDF framework of vCard profile is used to represent ecos:Address in the ECOS ontology model. An example of vCard schema used in ECOS model is as follows:

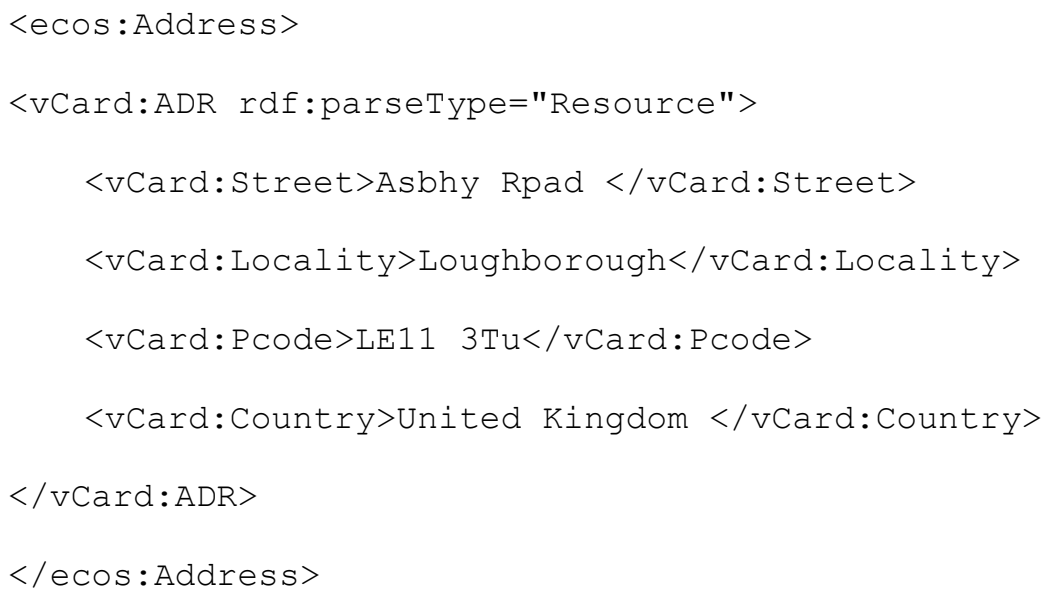

\section{Appendix B}

\section{Standard Classifications}

Classifications gather and organize information meaningfully and systematically into a standard format that can be useful for determining the similarity of ideas, events, objects or persons. The classification means the creation of an exhaustive and structured set of mutually exclusive and well-described categories, generally presented as a hierarchy of numeric or alphabetical codes assigned to them. Different international bodies have given classifications on matters such as economics, demographics, labour, health, education, social welfare, geography, environment and tourism. Some of the standard classifications used in this paper are:

- ISIC http://unstats.un.org/unsd/cr/registry/regcst.asp?Cl=17 (International Standard for Industrial Classification): It is a standard developed by the United Nations Statistical Division for classifying productive economic activities (i.e. the same raw materials, process of production, skills or technology). The ISIC system is now used widely by governments and international bodies as a way if classifying data according to economic activity. One key purpose of the code is to standardize data collection and promote international comparability. The entire ISIC classification is based on four levels, where level 1 includes 17 sections identified by alphabetical letters A to Q, level 2 covers 62 divisions identified by two-digit numerical codes, level 3 is 
defined by 161 groups identified by three-digit numerical codes and level 4 includes 298 classes represented with 4 digit code. For example:

Sector: I - Transport, storage and communications

Division: 64 - Post and telecommunications

Group: 641 - Post and courier activities

Class: 6411 - National post activities

- $\quad$ CPC http://unstats.un.org/unsd/cr/registry/regcst.asp?Cl=16 (Central Product Classification), defined by UN Statistical Division, constitutes a comprehensive classification of all goods and services. CPC presents categories for all products that can be the object of domestic or international transactions or that can be entered into stocks. It includes products that are an output of economic activity, including transportable goods, nontransportable goods and services. The classification structure of CPC comprises: Sections - one digit code; Divisions - two-digit code; Groups - three-digit code; Classes - four-digit code; Subclasses - five-digit code. For example,

Sector: 8 - Business and production services

Division: 84 - Telecommunications, broadcasting and information supply services

Group: 841 - Telephony and other telecommunications services

Class: 8411 - Carrier services

Subclass: 84110 - Carrier services

- $\quad$ NUTS http://ec.europa.eu/eurostat/ramon/nuts/basicnuts_regions_en.html (Nomenclature of Territorial Units for Statistics), developed by the European Union, is a geocode standard for referencing the administrative divisions of countries. This code begins with a two-letter code referencing the country, followed by 3 level codes. The three levels represent NUTS 1 (e.g. region, states etc), NUT 2 (e.g. county, province, etc) and NUT 3 (city, area, etc) respectively.

UK: United Kingdom

UKF: East Midlands, England

UKF2: Leicestershire, Rutland and Northamptonshire 


\section{UKF22: Leicestershire CC and Rutland}

- ISCO http://www.ilo.org/public/english/bureau/stat/isco/index.htm (International Standard Classification of Occupations) is standard structure developed by UN Statistical Division. This classification organizes jobs into a clearly defined set of groups according to the tasks and duties undertaken in the job. The classification structure of ISCO includes 4 levels: Level 1- Major groups (10), Level 2: Sub-major groups (28), Level 3Minor groups (118) and Level 4- Unit groups (390).

Major: 1 - Managers

Sub-major: 12 - Administrative and commercial managers

Minor: 121 - Business services and administration managers

Unit: 1211 - Finance managers

The former classifications are used in ECOS model for providing a standard vocabulary for competence representation.

\section{Appendix C}

\section{ECOS Coding}

An ontology must be coded in some formal language to express the concepts in the domain in a manner that computers can understand and manipulate easily. Several ontology languages have been developed during the last few years and have been used in the context of the semantic web. These ontology representation languages are logic based, frame based or web based. A comparison between all the existing ontology languages is provided in [14, 53]. The languages are extended versions of XML syntax facilitating greater machine interpretability and semantic interoperability. Ontology exchange language (XOL), Simple HTML Ontology extension (SHOE) and Ontology markup language (OML) are the primary extensions of the XML syntax. However, other popular ontology languages are RDF, RDF Schema (RDF-S) and OWL (Web Ontology Language) developed by World Wide Web consortium (W3C). These allow the specification of the semantics of data based on XML in a standardized and interoperable manner

The Web ontology language, OWL is the most expressive language for specifying, publishing and sharing ontologies. It facilitates greater machine interpretability of web content than that supported by XML, RDF, or any 
other language proposed in literature. It is the only standard web ontology language that provides formal semantics along with additional vocabulary. OWL mainly comes in three sub-languages, OWL Lite, OWL DL and OWL full, which are intended to be layered according to their increasing expressiveness. In this research, OWL DL is used to model the ECOS ontology as this enables the encoding, exchange and reuse of the ECOS ontology.

OWL describes the structure of an ontology by using some basic building blocks i.e. classes, properties and individuals. Classes are used to group and describe individuals with similar properties (implicit or explicit). Properties are binary relations on individuals, i.e. linking two individuals together or associating individuals with instances. In OWL, properties have multiple domains that connect a property with a class and multiple ranges to link the property with a class or instance. Individual represents instances of the described domain. The above three building blocks are also associated with relationship i.e. each class has a set of property, class has instance individual and individual has value for property. 


\section{References}

[1] Cross R., Thomas R., Dutra A. and Newberry C., "Using Network Analysis To Build a New Business," Organizational Dynamics, vol. 36, pp. 345-362, 2007.

[2] Nabuco O., Rosário J. M., Silva J. R. and Drira K., "Scientific collaboration and knowledge sharing in the virtual manufacturing network," International Federation of Automatic Control, Confernece, 2002.

[3] Huang N. and Diao S., "Ontology based enterprise knowledge integration," Robotics and Computer Integrated Manufacturing, 2007.

[4] Luczak H., "Knowledge management in virtual organizations," Services Systems and Services Management, 2005. Proceedings of ICSSSM '05. 2005 International Conference on, vol. 2, pp. 898-902 Vol. 2 , 2005.

[5] Prahalad C. K. and Hamel G., "The core competence of the corporation," Harvard Business Review, vol. 68, pp. 79-93, 1990.

[6] Zhanjun L., Victor R. and Karthik R., "Developing Engineering Ontology for Information Retrieval," ASME Transactions Journal of Computing and Information Science in Engineering, vol. 8, 2008.

[7] Sanchez R., "Understanding competence-based management: Identifying and managing five modes of competence," Journal of Business Research, vol. 57, pp. 518-532, 5. 2004.

[8] Schoemaker P., "How to link strategic vision to core capabilities," Sloan Management Review, vol. 534, pp. 6782, 1992.

[9] Yu Li, Biqing Huang, Wenhuang Liu, Hongmei Gon and Cheng Wu, "Enterprise competence modeling and management," Systems, Man, and Cybernetics, 2000 IEEE International Conference on, vol. 3, pp. 2121-2126 vol.3, 2000.

[10] Boucher X., Bonjour E. and Grabot B., "Formalisation and use of competencies for industrial performance optimisation: A survey," Computers in Industry, vol. 58, pp. 98-117, 2. 2007.

[11] Chiesa V. and Manzini R., "Competence levels within firms: A static and dynamic analysis," in CompetenceBased Strategic Management A. Heene and R. Sanchez, Eds. Wiley: Chichester, 1997, pp. 195-214.

[12] Gruber, T., What is an ontology? http://www-ksl.stanford.edu/kst/what-is-an-ontology.html

[13] Patel-Schneider P. F. and Horrocks I., "OWLWeb ontology language semantics and abstract syntax," The World Wide Web Consortium., 2004. 
[14] Corcho O., Fernandez-Lopez M. and Gomez-Perez A., "Methodologies, tools and languages for building ontologies. Where is their meeting point?," Data \& Knowledge Engineering, vol. 46, pp. 41-64, 2003.

[15] Yu B., Harding J. A. and Popplewell K., "Supporting enterprise design through multiple views," International Journal of Agile Management Systems, vol. 2, pp. 71-83, 2000.

[16] Vernadat F. B., "Enterprise modelling and integration (EMI): Current status and research perspectives," Annual Reviews in Control, vol. 26, pp. 15-25, 2002.

[17] Svieby K. E., The New Organizational Wealth-Managing and Measuring Intangible Assets. Berret-Koehler, 1997 ,

[18] Hall R., "A framework linking intangible resources and capabilities to sustainable competitive advantage," Strategic Management Journal, vol. 14, pp. 618, 1993.

[19] Jussupova-Mariethoz Y. and Probst A., "Business concepts ontology for an enterprise performance and competences monitoring," Computers in Industry, vol. 58, pp. 118-129, 2. 2007.

[20] Vernadat F., "UEML: towards a unified enterprise modelling language," International Journal of Production Research, vol. 40, pp. 4309-4321, 2002.

[21] Brandt S. C., Morbach J., Miatidis M., Theißen M., Jarke M. and Marquardt W., "An ontology-based approach to knowledge management in design processes," Computers \& Chemical Engineering, vol. 32, pp. 320-342, 1. 2008.

[22] Patil L., "Ontology-based exchange of product data semantics," Automation Science and Engineering, IEEE Transactions on [See also Robotics and Automation, IEEE Transactions on], vol. 2, pp. 213-225, 2005.

[23] Madni A. M., Lin W. and Madni C. C., "IDEONTM: An extensible ontology for designing, integrating, and managing collaborative distributed enterprises," Systems Engineering, vol. 4, pp. 35-48, 2001.

[24] Uschold M. and Jasper R., "A framework for understanding and classifying ontology applications," in 1999,

[25] Schlenoff C., Denno P., Ivester R., Libes D. and Szykman S., "An analysis and approach to using existing ontological systems for applications in manufacturing," AI- EDAM, vol. 14, pp. 257-270, 2000.

[26] Gottgtroy P., Kasabov N. and MacDonell S., "Chapter 21 evolving ontologies for intelligent decision support," in Capturing Intelligence, vol. Volume 1, Elie Sanchez, Ed. Elsevier, 2006, pp. 415-439.

[27] Fadel F., Fox M. S. and Gruninger M., "A generic enterprise resource ontology," In Proceedings of the Third Workshop on Enabling Technologies - Infrastructures for Collaborative Enterprises, pp. 86-92, 1994. 
[28] Goossenaerts J. B. M. and Pelletier C., "Ontology and Enterprise Modelling. In: Eijnatten," Participative Simulation Environment for Integral Manufacturing Enterprise Renewal. TNO Arbeid, pp. 41-52, 2002.

[29] Meta Data Coalition, "Open Information Model, Version 1.1," 1999.

[30] Gransier T. and Schönewolf W., "Validation of CIMOSA," Computers in Industry, vol. 27, pp. 95-100, 10. 1995.

[31] Kosanke K., "CIMOSA — Overview and status," Computers in Industry, vol. 27, pp. 101-109, 10. 1995.

[32] Arkin A., "Business proces modelling language," 2002. http://xml.coverpages.org/BPML-2002.pdf

[33] Allen C., "Competencies," HR-XML Consortium, Tech. Rep. 1, 2003. http://ns.hr-xml.org/2_0/HR-XML2_0/CPO/Competencies.pdf

[34] Lv Hexin and Zhu, Bin "Skill ontology-based semantic model and its matching algorithm," Computer-Aided Industrial Design and Conceptual Design, 2006. CAIDCD '06. 7th International Conference on, pp. 1-4, 2006.

[35] Pareto L. and Snis U. L., "An interactive visualization model for competence management: An integrative approach," in 2007,

[36] Harzallah M., Berio G. and Vernadat F., "Analysis and modeling of individual competencies: toward better management of human resources," Systems, Man and Cybernetics, Part A, IEEE Transactions on, vol. 36, pp. 187-207, 2006.

[37] Schmidt A. and Kunzmann C., "Towards a human resource development ontology for combining competence management and technology-enhanced workplace learning," in On the Move to Meaningful Internet Systems 2006: OTM 2006 Workshops, vol. 4278, Anonymous 2006, pp. 1078-1087.

[38] Draganidis F., Chamopoulou P. and Mentzas G., "An ontology based tool for competency management and learning paths", 6th International Conference on Knowledge Management" Graz, Austria, 2006,

[39] Tarassov V., Sandkuhl K. and Henoch B., "Using ontologies for representation of individual and enterprise competence models," Research, Innovation and Vision for the Future, 2006 International Conference on, pp. 206-213, 2006.

[40] Pépiot G., Cheikhrouhou N., Furbringer J. and Glardon R., "UECML: Unified Enterprise Competence Modelling Language," Computers in Industry, vol. 58, pp. 130-142, 2. 2007.

[41] Sanchez R., "Understanding competence-based management: Identifying and managing five modes of competence," Journal of Business Research, vol. 57, pp. 518-532, 5. 2004. 
[42] Canavesio M. M. and Martinez E., "Enterprise modelling of a project-oriented fractal company for SMEs networking," Computers in Industry, vol. 58, pp. 794-813, 12. 2007.

[43] Harding J. A., Yu B. and Popplewell K., "Organisational and functional views of a small manufacturing enterprise," International Journal of Business Performance Management, vol. 1, pp. 338-352, 1999.

[44] Casey M. and Pahl C., "Web Components and the Semantic Web," Electronic Notes in Theoretical Computer Science, vol. 82, pp. 156-163, 4. 2003.

[45] Camarinha-Matos L., Afsarmanesh H. and Osorio A. L., "Flexibility and safety in a Web-based infrastructure for virtual enterprises," International Journal of Computer Integrated Manufacturing, vol. 14, 2001.

[46] Xu Hui, "Applying Semantic Web Services to Automate Network Management," Industrial Electronics and Applications, 2007. ICIEA 2007. 2nd IEEE Conference on, pp. 461-466, 2007.

[47] Lastra J. L. M., "Semantic web services in factory automation: fundamental insights and research roadmap," Industrial Informatics, IEEE Transactions on, vol. 2, pp. 1-11, 2006.

[48] Brickley D. and Miller L., "FOAF vocabulary specification 0.9," 2007. http://xmlns.com/foaf/spec/

[49] Halpin H., Suda B. and Walsh N., "An ontology for vCards," 2006. http://www.w3.org/2006/vcard/ns

[50] Guarino N., "Formal Ontology in information systems," FOIS, pp. 3-15, 1998.

[51] Guarino N. and Giaretta P., "Ontologies and knowledge bases: towards a terminological clarification," In Mars, N., Editor, Towards very Large Knowledge Bases: Knowledge Building and Knowledge Sharing, pp. 25-32, 1995.

[52] Noy N. F. and McGuniness D. L., "Ontology Development 101: A guide to creating your first ontology," Standford Knowledge Systems Laboratory Technical Report KSL-01-05 and Standford Medical Informatics Technical Report SMI-2001, Standford University, 2001.

[53] Gómez-Pérez A. and Suárez-Figueroa M. C. E., Evaluation of $\operatorname{RDF}(S)$ and DAML+OIL Import/Export Services within Ontology Platforms., vol. 2972, 2004, pp. 109-118.

[54] Miles A., Matthews B., Wilson M. D. and Brickley D., "SKOS core: Simple knowledge organisation for the web," in 2005,

[55] Kumar M., Vrat P. and Shankar R., "A fuzzy goal programming approach for vendor selection problem in a supply chain," Computer and Industrial Engineering, vol. 46, pp. 69-85, 2004. 
[56] Fuqing Z., Yi H. L. and Dongmei Y., "A multi-objective optimization model of the partner selection problem in a virtual enterprise and its solution with genetic algorithms," IJAMT, vol. 28, pp. 1246-1253, 20086.

[57] Sari B. and Sen T., "Ahp model for the selection of partner companies in virtual enterprises," IJAMT, vol. 38, pp. 367-376, 2008.

[58] ISO, "ISO 10303-1 - industrial automation systems and integration - product data representation and exchange part 1: Overview and fundamental principles," Geneva, 1994.

[59] Uschold M., King M., Moralee S. and Zorgios Y., "The enterprise ontology," The Knowledge Engineering Review , , Special Issue on Putting Ontologies to Use, Vol. 13, pp 31-89, 1998.

[60] Schlenoff C. and Uschold M., "Knowledge engineering and ontologies for autonomous systems: 2004 AAAI Spring Symposium," Robotics and Autonomous Systems, vol. 49, pp. 1-5, 11/30. 2004.

[61] Waldt D. and Drummond R., "EBXML: The Global Standard for Electronic Business,"

[62] H. K. Lin and J. A. Harding, "A manufacturing system engineering ontology model on the semantic web for inter-enterprise collaboration," Computers in Industry, vol. 58, pp. 428-437, 6. 2007.

[63] Iannella R., "Representing vCard objects in RDF/XML," W3C, 2001. http://www.w3.org/TR/vcard-rdf

[64] Khilwani N., Harding J. A., Choudhary A. K., "Semantic web in manufacturing”, Proceedings of the Institution of Mechanical Engineers. Part B. Journal of engineering manufacture, Vol. 223(7), pp. 905-924, 2009

[65] Plisson J., Ljubic P., Mozetic I, Lavrac N., “An Ontology for Virtual Organization Breeding Environment”, IEEE Transactions on Systems, Man and Cybernatics- Part C: Applications and Reviews, Vol. 37 (6), 1327-1341, 2007.

[66] Connolly D., Miller L., "RDF Calendar - an application of the Resource Description Framework to iCalendar Data", http://www.w3.org/TR/rdfcal/ , 2005

[67] Penrose E., "The Theory of the Growth of the Firm”, New York, John Wiley and Sons, ISBN 9780198289777, 1959

[68] Barney, J. B. “Strategic Factor Markets: Expectations, Luck and Business Strategy”, Management Science, Vol. 32, pp. 1231-1241. 1986

[69] Barney, J. B. 'Firm Resources and Sustained Competitive Advantage', Journal of Management, Vol. 17, No. 1, pp. 99-120. 1991 
[70] Prahalad, C. K., and Hamel, G. "The Core Competence of the Corporation”, Harvard Business Review, Vol. 68, No. 3, pp. 79-91. 1990

[71] Rumelt, R. P. "Theory, Strategy and Entrepreneurship, in the Competitive Challenge”, David Teece (ed.), Ballinger Publishing Co., Cambridge, MA, pp. 137-157, 1987

[72] Eklöf M. and Mårtenson C., Ontological Interoperablilty. Technical Report, FOI-R1943SE, FOI, Sweden, 2006

[73] Bizer Christian, Heath Tom, Berners-Lee Tim Linked Data - The Story So Far. International Journal on Semantic Web and Information Systems (IJSWIS), Vol. 5(3), Pages 1-22, 2009 


\section{List of Tables and Figures (Captions)}

Table 1: ECOS Ontology Description

Figure 1: Structure of Enterprise

Figure 2: ECOS Ontology

Figure 3: Idea behind ECOS-card

Figure 4: Sample ECOS-card with Classification list

Figure 5: Classification Code as Semantic Web Resource

Figure 6: ECOS-card with blanks for Classification Codes

Figure 7: ECOS-card in two formats

Figure 8: Snippet of ECOS Card

Figure 9: Storing Competence in two formats

Figure 10: Links between ECOS-card, Classifications and Ontologies

Figure 11: Example for Network Analysis

Figure 12: Linked Open Data 
Table 1: ECOS Ontology Description

\begin{tabular}{|c|c|c|c|}
\hline Concept & Properties & Ontologies/Standards & Restrictions \\
\hline \multicolumn{4}{|l|}{ General Information } \\
\hline Company Name & ecos:name|ecos:uri & & \\
\hline Address & ecos:address | ecos:code & $\begin{array}{c}\text { vCard (address) } \\
\text { NUTS (code) }\end{array}$ & \\
\hline Summary & xsd:string & & \\
\hline Contact Person & ecos:person |ecos:code & $\begin{array}{c}\text { vCard (person) } \\
\text { ISCO (code) }\end{array}$ & \\
\hline Key Person & ecos:person |ecos:code & $\begin{array}{c}\text { vCard (person) } \\
\text { ISCO (code) }\end{array}$ & \\
\hline
\end{tabular}

\begin{tabular}{|c|c|c|c|}
\hline \multicolumn{4}{|l|}{ Business Detail } \\
\hline Sector & ecos: code & SectorCode (code) & \\
\hline Product/Service & $\begin{array}{l}\text { ecos:name | ecos:code | } \\
\text { ecos:detail }\end{array}$ & CPC/ISIC (code) & \\
\hline \begin{tabular}{|l|} 
Customer \\
\end{tabular} & ecos:Enterprise & ecos (Enterprise) & \\
\hline Preference & $\begin{array}{l}\text { ecos:type | ecos:code | } \\
\text { ecos:weight }\end{array}$ & $\begin{array}{c}\text { CPC/ISIC/NUTS/ISCO } \\
\text { (code) }\end{array}$ & $\begin{array}{l}\text { type }=\{\text { sector, region, } \\
\text { process, product }\}\end{array}$ \\
\hline Financial & $\begin{array}{l}\text { ecos:name | ecos:value| } \\
\text { ecos:time }\end{array}$ & iCalendar (time) & \\
\hline \multicolumn{4}{|l|}{ Specific Information } \\
\hline Resource & $\begin{array}{l}\text { ecos:name | ecos:detail | } \\
\text { ecos:code | ecos:type }\end{array}$ & CPC/ISIC (code) & $\begin{array}{l}\text { type }=\{\text { material, non- } \\
\text { material }\}\end{array}$ \\
\hline Process & $\begin{array}{l}\text { ecos:name |ecos:detail |ecos: } \\
\text { code }\end{array}$ & ISIC (code) & \\
\hline Unit & $\begin{array}{l}\text { ecos:name |ecos:detail |ecos: } \\
\text { code |ecos:responsibility | eco }\end{array}$ & ISIC (code) & \\
\hline
\end{tabular}




\begin{tabular}{|c|c|c|c|}
\hline & $s$ :actor & & \\
\hline Skill & $\begin{array}{l}\text { ecos:name |ecos:detail |ecos: } \\
\text { code }\end{array}$ & ISIC (code) & \\
\hline Plan & $\begin{array}{l}\text { ecos:name |ecos:detail |ecos: } \\
\text { code }\end{array}$ & ISIC (code) & \\
\hline \multicolumn{4}{|l|}{ Business Record } \\
\hline Relation & ecos:type|ecos:Enterprise & ecos (Enterprise) & $\begin{array}{l}\text { type }=\{\text { investor, } \\
\text { supplier, customer, } \\
\text { competitor, } \\
\text { collaborator }\}\end{array}$ \\
\hline Achievement & $\begin{array}{l}\text { ecos:name | ecos:detail | } \\
\text { ecos:code | ecos:type }\end{array}$ & CPC/ISIC (code) & $\begin{array}{l}\text { type }=\{\text { patent, } \\
\text { standard, publication }\}\end{array}$ \\
\hline Past Project & $\begin{array}{l}\text { ecos:name | ecos:detail | } \\
\text { ecos:code | ecos:time| } \\
\text { ecos:partner }\end{array}$ & $\begin{array}{l}\text { ecos } \text { (partner) | iCalendar } \\
\text { (time) } \mid \text { ISIC/CPC (code) }\end{array}$ & \\
\hline
\end{tabular}




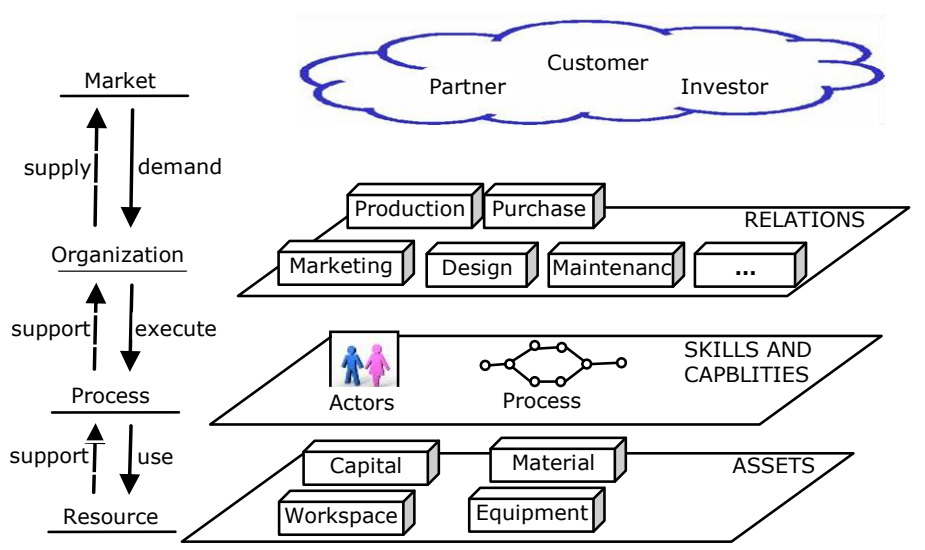

Figure 1: Structure of Enterprise

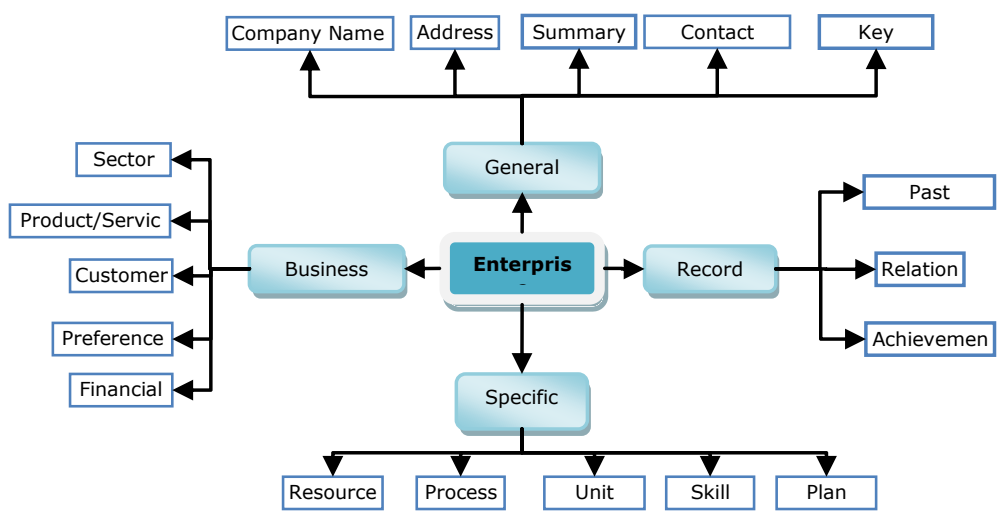

Figure 2: ECOS Ontology

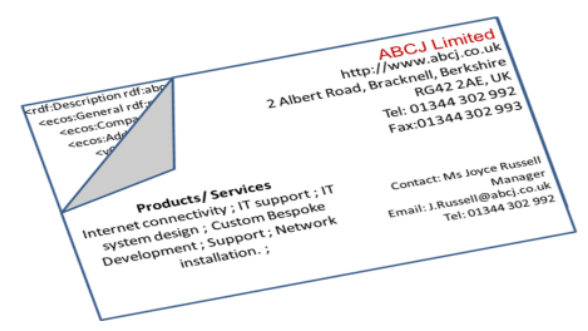

Figure 3: Idea behind ECOS-card 


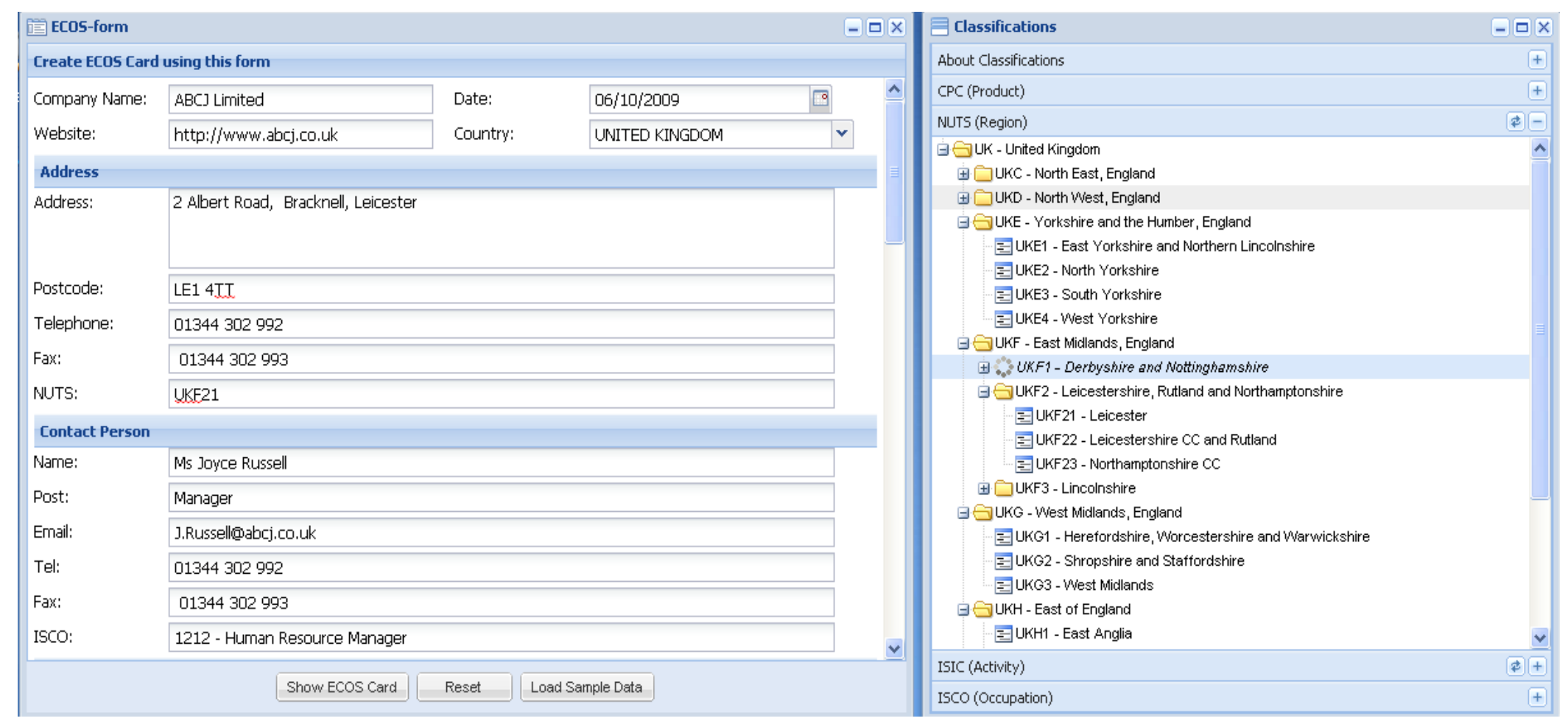

Figure 4: Sample ECOS-card with Classification list 
Web Resource

\begin{tabular}{|c|c|}
\hline \multicolumn{2}{|c|}{$\begin{array}{l}\text { 8- Business and production services } \\
\text { 83- Other professional, technical and business services } \\
\text { 831 - Management consulting and management services; information technology services } \\
8313 \text { - Information technology (IT) consulting and support services } \\
\mathbf{8 3 1 3 2} \text { - IT support services }\end{array}$} \\
\hline Semantic Web Resource & \\
\hline \multicolumn{2}{|c|}{$\begin{array}{l}\text { <rdf:Description rdf:about="http://kmm.lboro.ac.uk/classification/cpc\#83132"> } \\
\text { <skos:broadMatch rdf:resource="http://kmm.lboro.ac.uk/classification/cpc\#8313"/> } \\
\text { <skos:hiddenLabel>83132</skos:hiddenLabel> } \\
\text { <skos:prefLabel>IT support services</skos:prefLabel> } \\
\text { <rdf:type rdf:resource="http://www.w3.org/2004/02/skos/core\#Concept"/> } \\
\text { </rdf:Description> }\end{array}$} \\
\hline
\end{tabular}

Figure 5: Classification Code as Semantic Web Resource

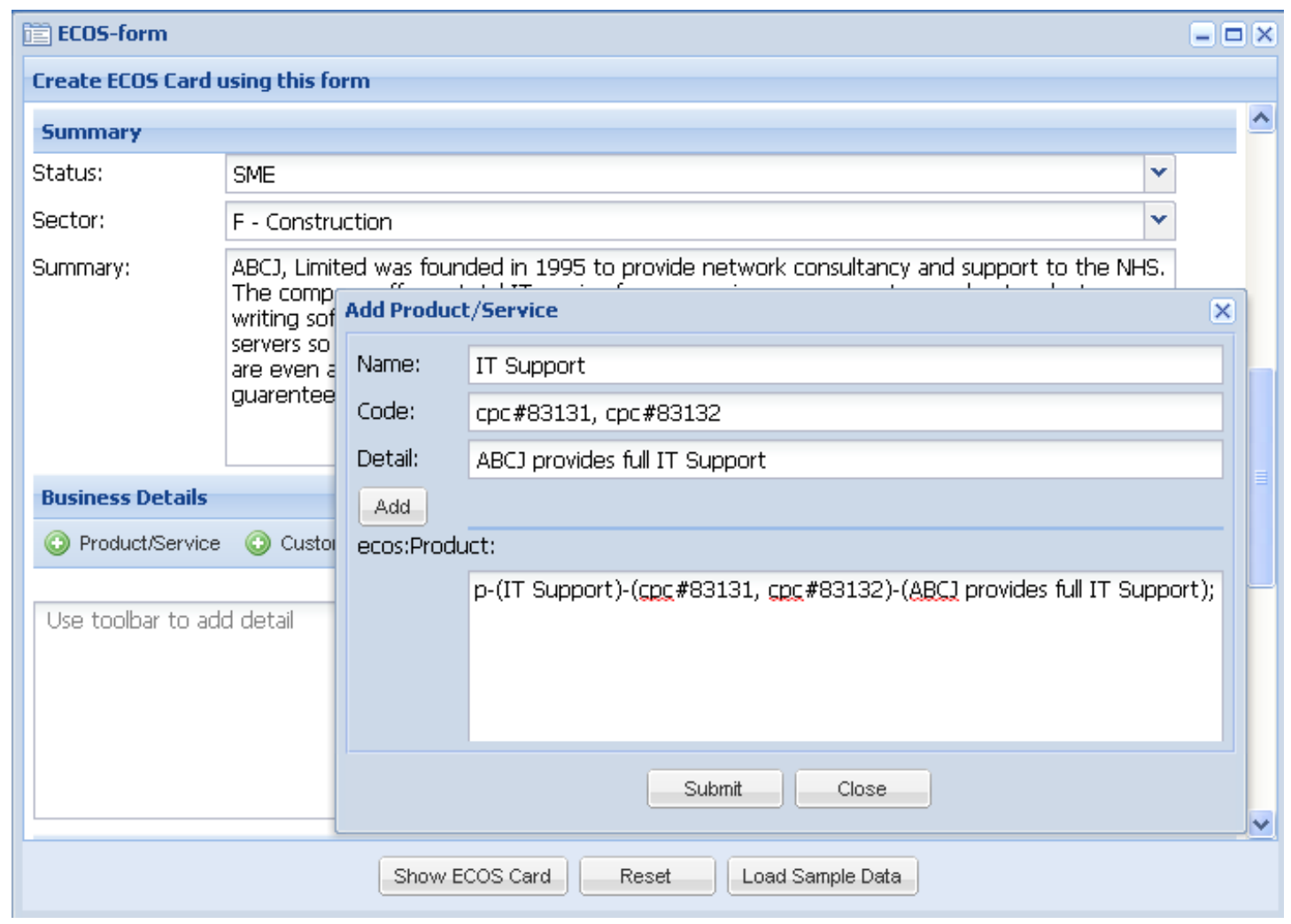

Figure 6: ECOS-card with blanks for Classification Codes 


\begin{tabular}{|c|c|c|c|c|c|}
\hline Your ECOS Card & \multirow[t]{2}{*}{$x$} & \multicolumn{3}{|c|}{ Your ECOS Card } & \multirow[t]{2}{*}{$x$} \\
\hline Card & & Card & RDF & & \\
\hline 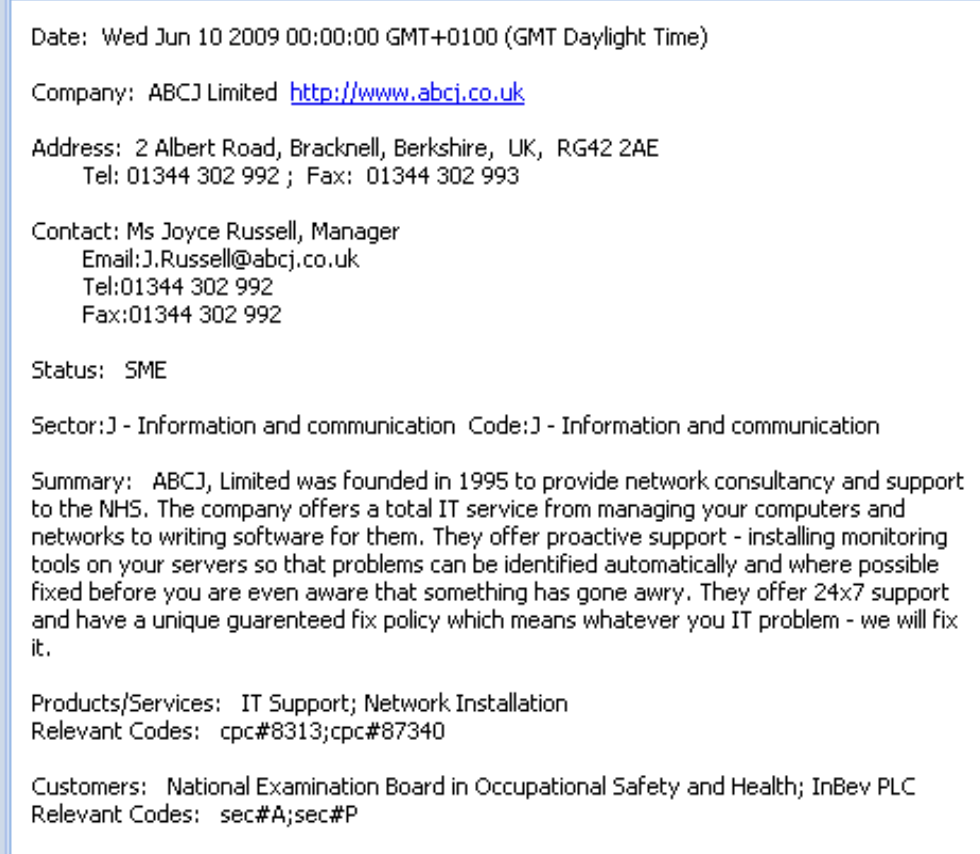 & $\wedge$ & \multicolumn{3}{|c|}{ 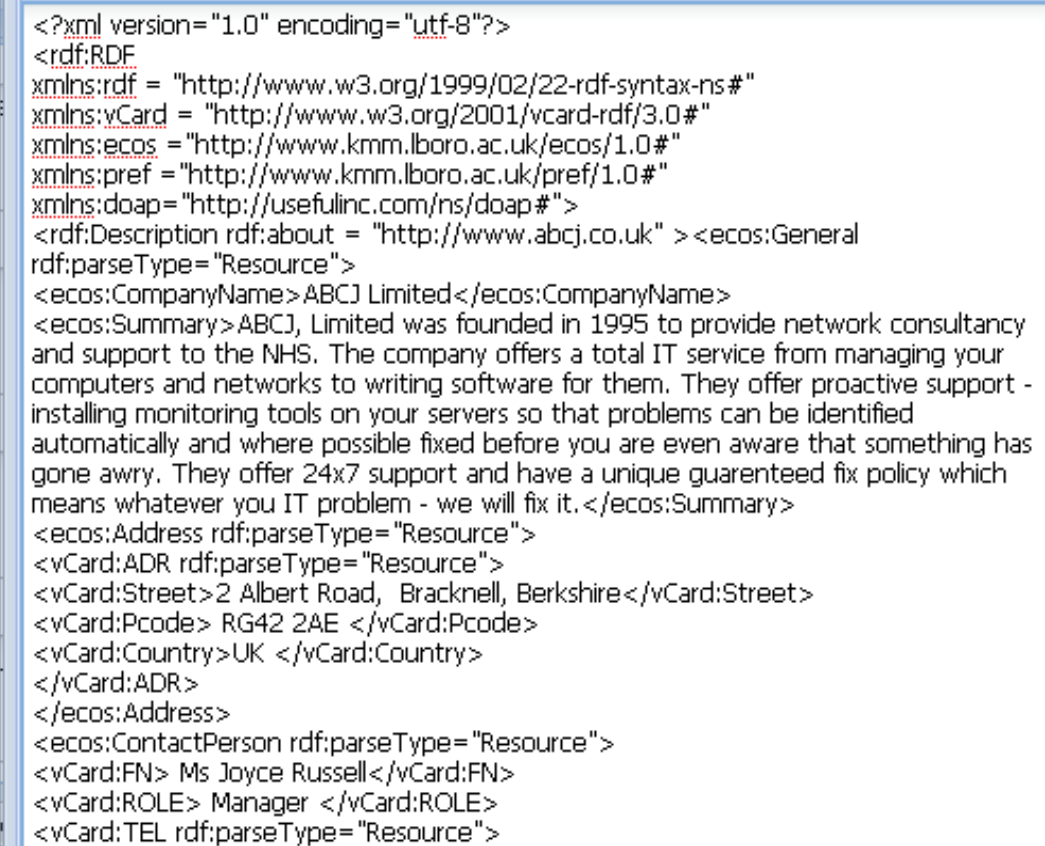 } & 스 \\
\hline & & & & & \\
\hline
\end{tabular}

Figure 7: ECOS-card in two formats 


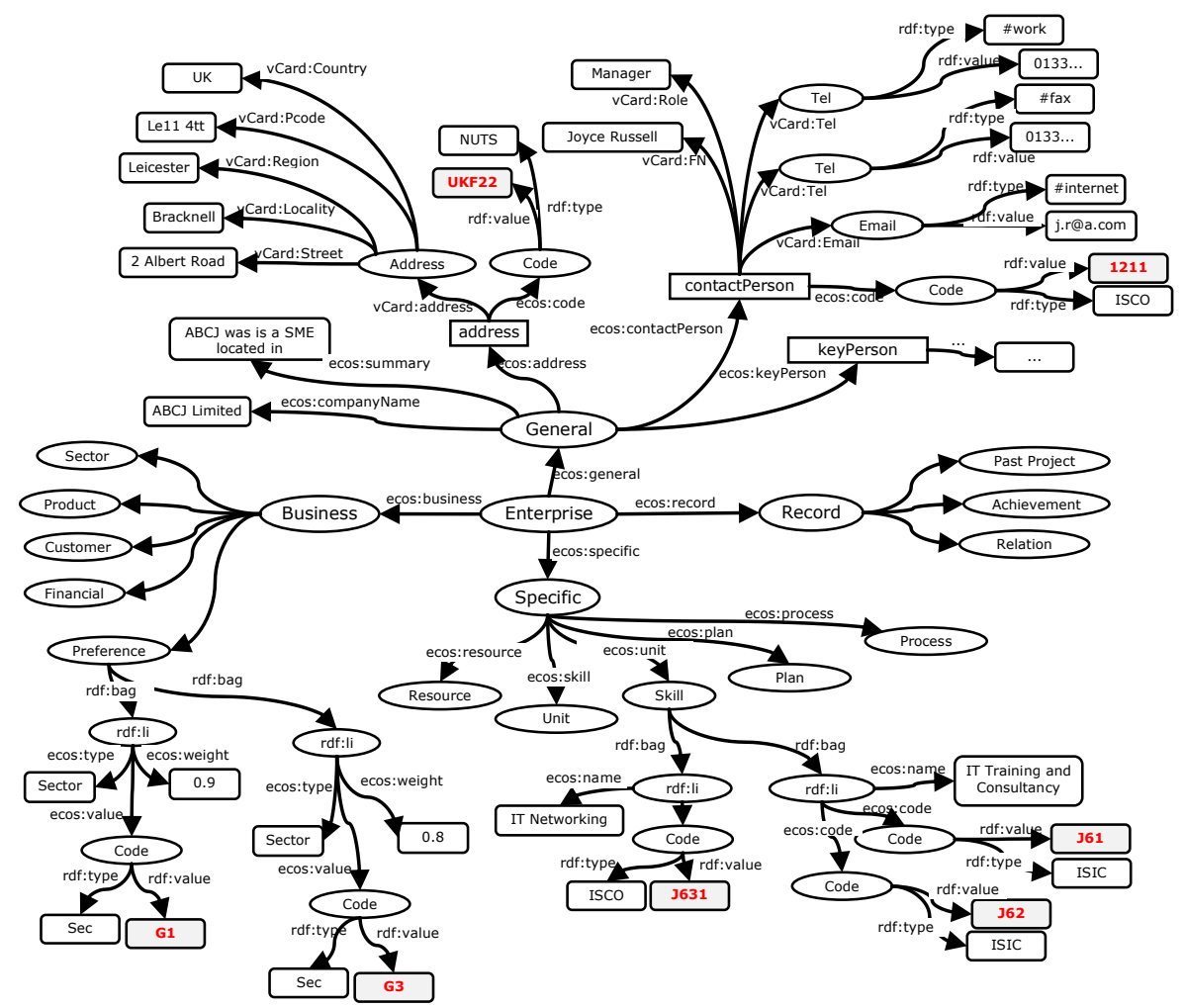

Figure 8: Snippet of ECOS Card

\begin{tabular}{|c|c|}
\hline $\begin{array}{l}\text { They offer a total IT support from } \\
\text { managing your computers and } \\
\text { networks and for writing software } \\
\text { for them. }\end{array}$ & RDF/XML \\
\hline $\begin{array}{l}\quad \text { HTML/XML } \\
\begin{array}{|l|}\text { Name: IT Support } \\
\text { Code: cpc\#83131, cpc\#83132 } \\
\text { Detail: ABCJ provides full IT } \\
\text { support. }\end{array}\end{array}$ & $\begin{array}{l}\text { <ecos:Product> } \\
\text { <ecos:name>IT Support</ecos:name> } \\
\text { <ecos:code rdf:parseType="Resource"> } \\
\text { <rdf:value >cpc\#83131</rdf:value> } \\
\text { <rdf:type rdf:resource= "http://kmm.lboro.ac.uk/classification/cpc\#83131" /> } \\
\text { </ecos:code> } \\
\text { <ecos:code rdf:parseType="Resource"> } \\
\text { <rdf:value>cpc\#83132</rdf:value> } \\
\text { <rdf:type rdf:resource="http://kmm.lboro.ac.uk/classification/cpc\#83132"/> } \\
\text { </ecos:code> } \\
\text { <ecos:detail>ABCJ provides full IT support</ecos:detail> } \\
\text { </ecos:Product> }\end{array}$ \\
\hline
\end{tabular}

Figure 9: Storing Competence in two formats 


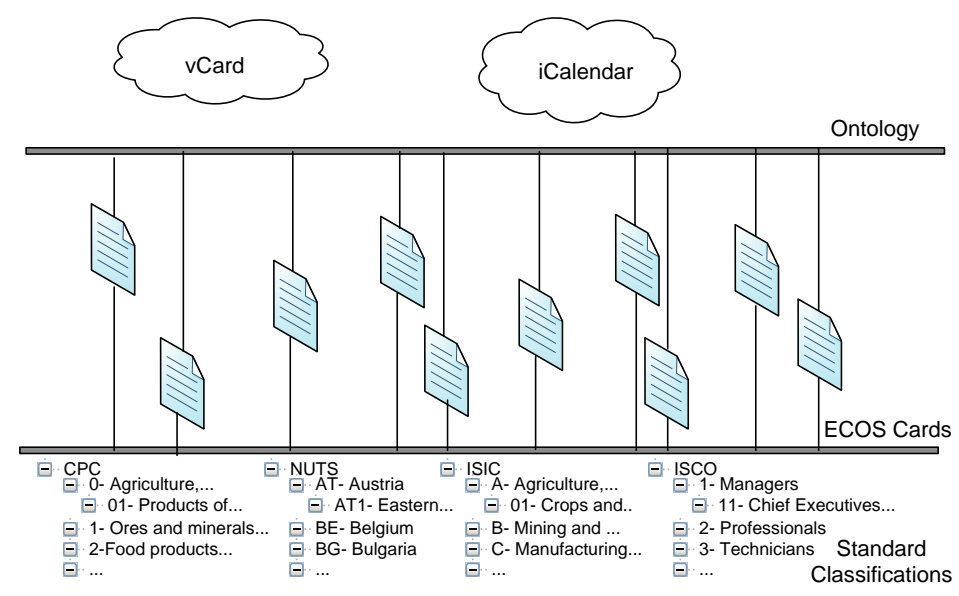

Figure 10: Links between ECOS-card, Classifications and Ontologies

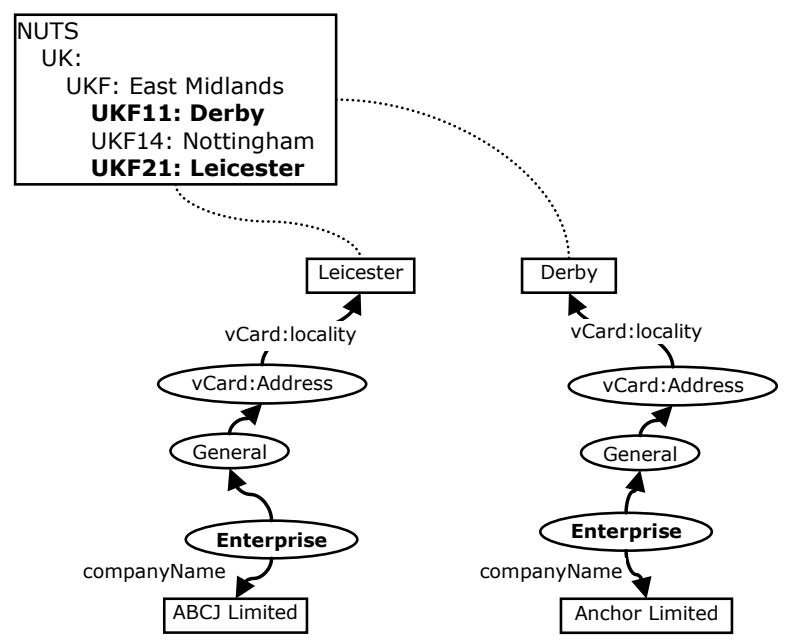

Figure 11: Example for Network Analysis 


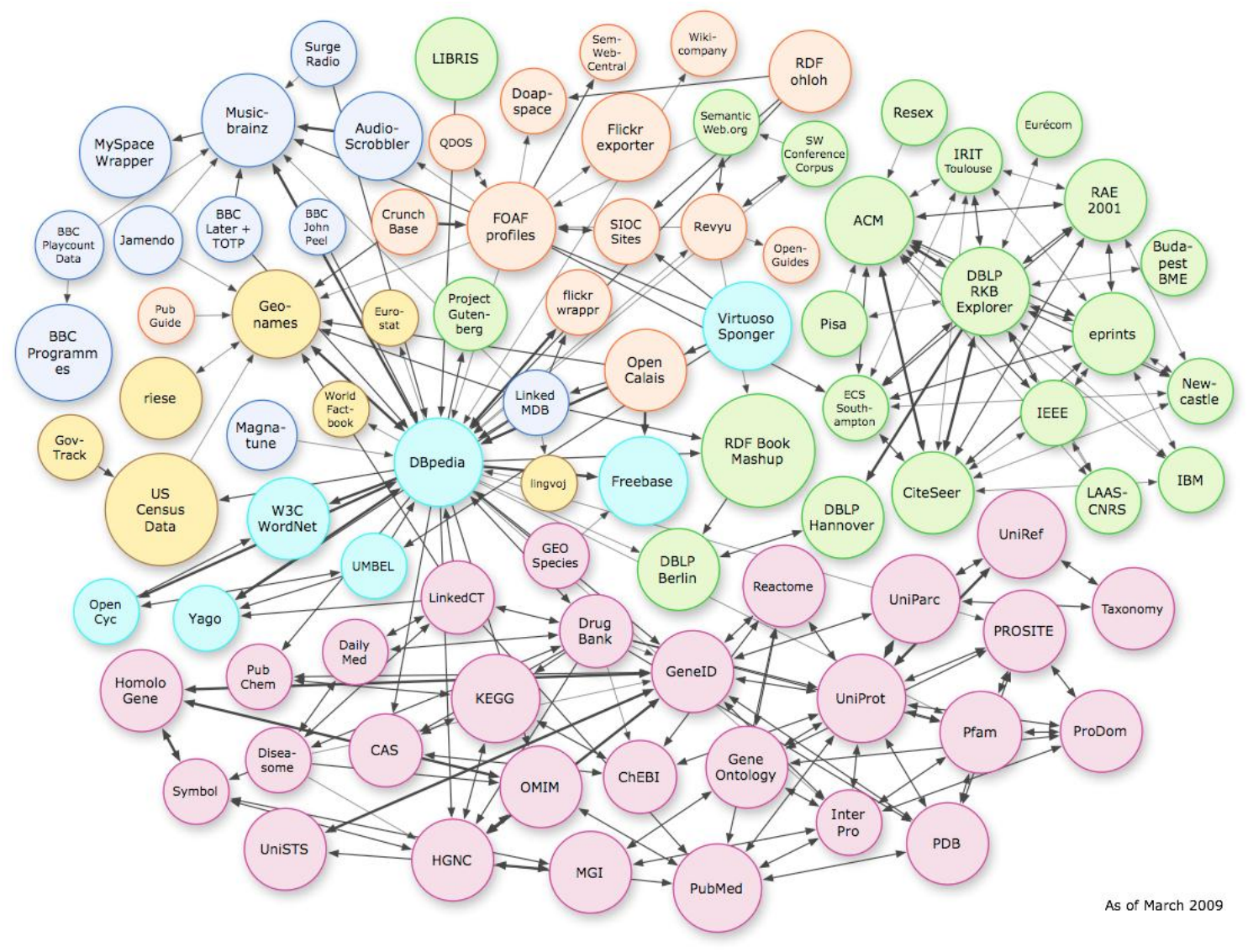

Figure 12: Linked Open Data 